\title{
GFAP isoforms control intermediate filament network dynamics, cell morphology, and focal adhesions
}

\author{
Martina Moeton ${ }^{1}$ - Oscar M. J. A. Stassen ${ }^{1,6}$ - Jacqueline A. Sluijs ${ }^{2}$ • \\ Vincent W. N. van der Meer ${ }^{1} \cdot$ Liselot J. Kluivers $^{1} \cdot$ Hedde van Hoorn $^{3}$. \\ Thomas Schmidt $^{3}$ Eric A. J. Reits ${ }^{4}$ Miriam E. van Strien ${ }^{1,2} \cdot$ Elly M. Hol $^{1,2,5}$
}

Received: 29 September 2015/Revised: 12 April 2016/Accepted: 21 April 2016/Published online: 3 May 2016

(C) The Author(s) 2016. This article is published with open access at Springerlink.com

\begin{abstract}
Glial fibrillary acidic protein (GFAP) is the characteristic intermediate filament (IF) protein in astrocytes. Expression of its main isoforms, GFAP $\alpha$ and GFAP $\delta$, varies in astrocytes and astrocytoma implying a potential regulatory role in astrocyte physiology and pathology. An IF-network is a dynamic structure and has been functionally linked to cell motility, proliferation, and morphology. There is a constant exchange of IF-proteins with the network. To study differences in the dynamic properties of GFAP $\alpha$ and GFAP $\delta$, we performed fluorescence recovery after photobleaching experiments on astrocytoma cells with fluorescently tagged GFAPs. Here, we show for the first time that the exchange of GFP-GFAP $\delta$ was significantly slower than the exchange of GFP-GFAP $\alpha$ with the IF-
\end{abstract}

Electronic supplementary material The online version of this article (doi:10.1007/s00018-016-2239-5) contains supplementary material, which is available to authorized users.

Elly M. Hol

e.m.hol-2@umcutrecht.nl

1 Netherlands Institute for Neuroscience, Royal Netherlands Academy of Arts and Sciences, Amsterdam, The Netherlands

2 Department of Translational Neuroscience, Brain Center Rudolf Magnus, University Medical Center Utrecht, Universiteitsweg 100, 3584 CG Utrecht, The Netherlands

3 Physics of Life Processes, Leiden Institute of Physics, Leiden, The Netherlands

4 Cell Biology and Histology, AMC Medical Center, Amsterdam, The Netherlands

5 Swammerdam Institute for Life Sciences, Center for Neuroscience, University of Amsterdam, Amsterdam, The Netherlands

6 Present Address: Soft Tissue Biomechanics \& Engineering, Department of biomedical engineering, Eindhoven University of Technology, Eindhoven, The Netherlands network. Furthermore, a collapsed IF-network, induced by GFAP $\delta$ expression, led to a further decrease in fluorescence recovery of both GFP-GFAP $\alpha$ and GFP-GFAP $\delta$. This altered IF-network also changed cell morphology and the focal adhesion size, but did not alter cell migration or proliferation. Our study provides further insight into the modulation of the dynamic properties and functional consequences of the IF-network composition.

Keywords GFAP · Astrocytoma · FRAP .

Intermediate filaments

\section{Introduction}

Intermediate filaments (IFs) are part of the cytoskeleton. Together with actin filaments and microtubules, they form an integrated system that regulates many cellular processes, such as cell morphology, cell signaling, cell migration, and proliferation [1-4]. The main IF protein expressed in astrocytes is glial fibrillary acidic protein (GFAP). The ten different GFAP isoforms, of which GFAP $\alpha$ is the canonical isoform, are formed by alternative splicing $[5,6]$. The function of GFAP and its isoforms is still elusive, but there is emerging evidence that at least one isoform, GFAP $\delta$, alters the properties of the IF network. GFAP $\delta$ differs from GFAP $\alpha$ only in its C-terminal tail, and in non-pathological human brains, and is expressed in specific types of astrocytes, including the adult neural stem cells in the human subventricular zone and subpial astrocytes [7-9]. The GFAP $\delta$ protein has a unique 41 amino acids long C-terminal tail $[6,7]$ and is one amino acid shorter than the canonical GFAP $\alpha$ protein [10]. In pathological conditions, GFAP $\delta$ is expressed in certain types of reactive gliosis and glial tumors [11-15]. The tail of GFAP $\delta$ disables the 
protein to form homodimers making it impossible to selfassemble [16]. GFAP $\delta$ is able to form heterodimers with other type III IF proteins and can, therefore, be integrated in an IF network. Depending on the level of expression and the concentration of other IFs present, GFAP $\delta$ is either tolerated in the network or it causes the whole IF network to collapse in the perinuclear region [7, 17]. Assembly experiments in a cell free environment showed that GFAP networks start to collapse when there is more than $10 \%$ of GFAP $\delta$ protein present in the network [17].

In the cell, IF proteins are present in a soluble form in the cytoplasm and in filamentous structures that form an important part of the cell's cytoskeleton $[18,19]$. These IF networks are highly motile structures that are constantly rearranged. The proteins within the filaments are also dynamic, since there is an active exchange between the filamentous and non-filamentous pool of IF proteins [2023]. IF networks that are already formed can be actively disassembled by phosphorylation of IF proteins, whereas the lack of dephosphorylation will hamper new IF network assembly [24, 25]. It has been shown that phosphorylation of GFAP at the N-terminal head domain by kinases, such as Aurora B or CF kinase, is important for proper dissociation from the filaments during cytokinesis [25-28].

Previously, we showed both in vitro and in vivo that physiological levels of GFAP $\delta$ are well tolerated in a GFAP $\alpha$ network $[7,8,15,17]$, although it has also been shown in a cell free system and in vitro that a high expression of GFAP $\delta$ can lead to an IF network collapse [7, 16, 17]. These collapses resemble aggregates of GFAP proteins, which occur when cells are transfected with mutant R416W GFAP [29]. This is one of the mutations in GFAP that causes Alexander disease $(\mathrm{AxD})$, a fatal neurodegenerative disease characterized by leukodystrophy, macrocephaly, and psychomotor retardation [30]. A pathological hallmark of this disease is the presence of Rosenthal fibers, which are astrocytic aggregates that are comprised of GFAP, ubiquitinated proteins, and stress proteins, such as heat shock proteins like $\alpha \mathrm{B}$ crystallin (CRYAB) and heat shock protein 27 (HSP27) [29, 31-34], but also IF-associated proteins like plectin [35]. AxD mutations in GFAP and the subsequent collapse of the network influence astrocyte viability, morphology, and glutamate transport, and aggregates or accumulations of mutant AxD GFAP have a profound effect on astrocyte biology and physiology [36-39].

There is increasing evidence that GFAP $\delta$ changes IF properties $[17,40]$. Here, we studied in more detail the differences in dynamic exchange of GFAP $\alpha$ and GFAP $\delta$ with the IF network in vitro. Furthermore, we analyzed the functional consequences of GFAP $\alpha$ or GFAP $\delta$ expression by assessing the effect of the altered GFAP network on the dynamics and localization of other IF proteins in the cells, on cell morphology, and focal adhesions. We also determined the effect on cell migration and proliferation, since it has been reported that GFAP affects these processes [4, 41-43]. Investigating the dynamic properties of the different GFAP isoforms and the effects of the different GFAP networks on cellular functions will contribute to our understanding of the consequences of modulation of the GFAP network for astrocyte physiology and pathology.

\section{Methods}

\section{Cell culturing and transfections}

U251MG human astrocytoma cells (gift from A.M.W. van Dam, VU University Medical Center, Department of Anatomy and Neurosciences, Amsterdam, The Netherlands) and U343MG human astrocytoma cells (gift from Prof Dr. R. Quinlan, Durham University, Durham, UK) were cultured in DMEM Glutamax (Gibco) mixed 1:1 with Ham's F10 medium (Gibco) containing $10 \%$ Fetal bovine serum (FBS) (Gibco) and 10-U/mL penicillin streptomycin (P/S) (Invitrogen). Human embryonic kidney (HEK293T) cells were cultured in DMEM/Glutamax with $10 \%$ FBS, $1 \% \mathrm{P} / \mathrm{S}$, and $1 \%$ extra Glutamax (all Invitrogen). All cells were cultured in uncoated plastic flasks (Corning) at $37{ }^{\circ} \mathrm{C}$ in a humidified atmosphere, with $5 \% \mathrm{CO}_{2}$.

\section{Isolation of primary human astrocytes}

Primary human adult astrocytes were obtained from freshly dissected postmortem subcortical white matter of a 79-year-old female control donor (NBB 2010-038), with a postmortem delay of $<18$ hours (h) and a cerebrospinal fluid $\mathrm{pH}$ of 6.30 . The tissue was obtained from the Netherlands Brain Bank (NBB), which performs brain autopsies with short postmortem intervals. The brain donors gave informed consent for using the tissue and for accessing the extensive neuropathological and clinical information for scientific research, which is in compliance with ethical and legal guidelines [44]. The tissue was collected in 25-mL cold Hibernate A (Invitrogen), and mechanically dissociated into small pieces. The tissue was digested with $0.2 \%$ trypsin (Invitrogen) and $0.1 \%$ DNAseI (Invitrogen) at $37{ }^{\circ} \mathrm{C}$, while shaking for $30 \mathrm{~min}$ (min). Next, 2-mL FBS was added to the mixture, and subsequently, the cells were collected by centrifugation. The pellet was taken up in DMEM without phenol red containing $10 \%$ FBS, $2.5 \%$ Hepes, and $1 \% \mathrm{P} / \mathrm{S}$ (all Invitrogen), and the suspension was filtered through a $60-\mu \mathrm{m}$ mesh screen. Then, Percoll (Amersham/GE Healthcare) was added (half of the cell suspension volume), and this mixture was centrifuged at 3220 relative centrifugal force (rcf) at $4{ }^{\circ} \mathrm{C}$ for 30 min to separate cells, 
debris, and myelin. The second layer (glial cell containing fraction) was collected and washed with complete DMEM (containing $10 \% \mathrm{FBS}, 1 \% \mathrm{P} / \mathrm{S}, 2.5 \%$ Hepes, and $1 \%$ gentamycin, all Invitrogen). After centrifugation, the pellet was taken up in complete DMEM, and cells were seeded in a $6-\mathrm{cm}$ uncoated culture dish. Microglia adhered to the dish, and after $6 \mathrm{~h}$ at $37{ }^{\circ} \mathrm{C} / 5 \% \mathrm{CO}_{2}$, the medium, containing astrocytes, was taken off, centrifuged, and the microglia depleted pellet was seeded onto poly-L-lysinecoated wells [PLL, Sigma-Aldrich, $15 \mu \mathrm{g} / \mathrm{mL}$ in PBS, $1 \mathrm{~h}$ at room temperature (RT)] in DMEM/Ham's F12 GlutaMAX medium containing $5 \% \mathrm{FBS}, 1 \% \mathrm{P} / \mathrm{S}$, and $0.25 \%$ Fungizone (all Invitrogen).

\section{Plasmid construction, transient transfection, and virus production}

Expression vectors were prepared by cloning human GFAP $\alpha$ and human GFAP $\delta$ [7, 17, 29] full length cDNA sequences into the pIRES2EGFP (Clontech). For the GFAP $\delta$ constructs, the eGFP sequence was replaced by mCherry.

GFP tagged GFAP constructs were created by cloning human GFAP $\alpha$ and GFAP $\delta$ cDNA sequences [7] in frame after the eGFP sequence in peGFP using BAMHI and HindIII as restriction sites (Clontech) to create N-terminal eGFP tagged GFAPs. The N-terminal side was chosen for the eGFP tag, since GFAP $\alpha$ and GFAP $\delta$ differ in their C-terminal tail. All plasmids were sequenced.

Cells for fluorescence recovery after photobleaching (FRAP) experiments were transiently transfected using polyethylenimine (PEI) (Polysciences) or Lipofectamine (Invitrogen) according to manufacturer's descriptions. $2.5 \mu \mathrm{g}$ of plasmid DNA was used for PEI and $1.6 \mu \mathrm{g}$ for Lipofectamine [5] in subconfluent 24-wells plates.

Subsequently, to produce lentiviral vectors, the constructs were subcloned into a pRRL lenti backbone. Lentiviruses were produced as described before [45, 46] with some alterations. In short, $10 \times 10^{6}$ HEK $293 \mathrm{~T}$ cells were plated in a $15-\mathrm{cm}$ culture dish and transfected with a total of $90 \mu \mathrm{g}$ of the envelope (pMD2.G), packaging (pCMV-dR8.74) and p156RRL plasmid, containing different expression cassettes per dish, using PEI. In total, $90 \mu \mathrm{g}$ of DNA was mixed with PEI $(67.5 \mathrm{ng} / \mu \mathrm{L})$, incubated for $15 \mathrm{~min}$ at RT, and added dropwise to the cell culture. The culture medium was replaced $16 \mathrm{~h}$ after transfection, and the medium containing viral particles was collected $24 \mathrm{~h}$ after transfection. Supernatants were ultracentrifuged at 22,000 rpm (rotor SW28, Beckman-Coulter) for $2.5 \mathrm{~h}$. The resulting pellet was resuspended in phosphate-buffered saline (PBS) ( $\mathrm{pH} 7.4)$, aliquoted and stored at $-80{ }^{\circ} \mathrm{C}$ until further use.
To measure viral titers, a dilution series across five orders of magnitude of the viral stock solutions was made and HEK293T cells were transduced. After 2 days of incubation at $37{ }^{\circ} \mathrm{C}$, the number of transduced fluorescent cells at the different viral dilutions was counted, and the viral titer was determined in transducing units (TU)/mL.

\section{Creating stable cell lines}

For functional experiments, cell lines expressing GFAP isforms were created. U251 cells were transduced with lentiviral constructs with a multiplicity of infection of 10 . Medium was refreshed after $16 \mathrm{~h}$. To maintain a population of transduced cells, cells were sorted on their EGFP or mCherry expression using fluorescent activated cell sorting (FACS ARIA II, BD Bioscience, Franklin Lakes, NJ, USA). In between experiments, U251 cells were stained for GFAP to ensure that more than $70 \%$ of the cells were expressing the construct. The primary human astrocytes were checked for fluorescent reporter expression before any analysis to ensure cells were expressing GFAP isoforms.

\section{MTT assay}

To measure cell proliferation, an MTT(3-(4,5Dimethylthiazol-2-yl)-2,5-diphenyltetrazolium bromide) assay was performed. MTT is reduced into a soluble blue formazan product by mitochondrial enzymes in living cells only. Therefore, the amount of formed formazan is proportional to the amount of living cells present [47]. MTT assays were performed by plating cells in non-coated plastic 24-wells plates (Greiner). To quantify cells, medium was replaced by $500-\mu \mathrm{L}$ serum free medium containing $0.5-\mathrm{mg} / \mathrm{mL}$ MTT, which was incubated at $37^{\circ} \mathrm{C}$ for $2 \mathrm{~h}$. Cells were subsequently lysed in $100 \%$ DMSO, which dissolves the purple formazan resulting in a color change of the DMSO. The amount of purple formazan, and therefore the amount of cells able to metabolize the MTT, was measured using a Varioskan Flash (Thermo scientific, USA), measuring the absorbance at $570 \mathrm{~nm}$. Significance was tested with a Kruskal-Wallis test with Dunn's Multiple Comparison post hoc test on 3 independent experiments. Every measurement in the independent experiments was the average of a biological duplicate.

\section{Phospho-histone H3 quantification}

To determine the number of actively proliferating cells, U251 cells expressing GFAP isoforms were plated on noncoated coverslips and fluorescently stained for phosphohistone $\mathrm{H} 3$ (PHH3) together with the nuclear dye Hoechst 
(1:1000 dilution) (Invitrogen). Subsequently, micrographs were taken, the number of $\mathrm{PHH} 3$ positive, dividing, nuclei was counted using ImagePro software (version 6.3), and the percentage of dividing cells was calculated by dividing the number of $\mathrm{PHH} 3$ positive cells by total number of Hoechst positive nuclei. Per experiment, 5 fields of view were analyzed and averaged, each containing at least 50 cells. Data from separate experiments were corrected for inter-experimental variation as stated below. Significance was tested with a Kruskal-Wallis test with Dunn's post hoc test on data from 3 independent experiments.

\section{Migration assay}

To measure cell migration, a scratch assay was performed. U251 cells were plated in a 24 -wells plate $(100,000$ cells per well) coated with $20-\mu \mathrm{g} / \mathrm{mL}$ PLL at $37{ }^{\circ} \mathrm{C}$ for $1 \mathrm{~h}$. The confluent cell monolayer was scratched with a P10 plastic pipet tip. Pictures were taken using an Axiovert $135 \mathrm{M}$ (Zeiss) with a Sony XCD-X700 camera (Sony) at the time points indicated in the results. To quantify cell migration, the surface area not covered by cells was determined at different time points. The migration was calculated as the percentage of uncovered surface area compared with $t=0$. A mean of 9 pictures was measured per condition, in at least 3 separate experiments. Significance was tested with a Kruskal-Wallis test with Dunn's post hoc test.

\section{Single cell motility assay}

Single cell motility assays were performed on a Zeiss Axiovert 2000 inverted microscope (Zeiss, Jena, Germany). A single cell suspension was plated on PLL-coated glass dishes with four compartments (CELLview, Greiner bio-one, Alphen a/d Rijn, The Netherlands) and allowed to adhere for at least $8 \mathrm{~h}$. Dishes were kept on the microscope in a pre-heated and humidified incubation chamber (OKO labs) at $37{ }^{\circ} \mathrm{C}$ and $5 \% \mathrm{CO}_{2}$. Pictures were taken every 10 min with an Axi Aqua camera (Q imaging). Cell motility was measured by tracking single cells throughout all frames of the sequence and measuring the average velocity in $\mu \mathrm{m}$ per min using the manual tracking plugin from ImageJ (Rasband, W.S., ImageJ, U. S. National Institutes of Health, Bethesda, Maryland, USA, http:// imagej.nih.gov/ij/, 1997-2012 version 1.46f). Per experiment, at least 20 cells were analyzed per condition in at least 3 independent experiments. Data from separate experiments were corrected for inter-experimental variation as stated in the "Statistics and factor correction" section below. A Kruskal-Wallis test with Dunn's post hoc test was performed to test for significance. For the primary human astrocytes, which were not sorted, we checked for
GFP and mCherry expression to make sure that we only tracked transduced cells.

\section{Quantitative reverse transcriptase PCR (qPCR) analysis}

U251 cells were transduced like described before. Medium was refreshed after $16 \mathrm{~h}$. RNA was extracted 7 days after transduction. RNA was extracted from cells using TRIsure (Bioline, London, UK) and precipitated in isopropanol overnight $(\mathrm{O} / \mathrm{N})$. Five hundred nanograms of RNA was reverse transcribed into cDNA with a QuantiTect reverse transcription kit (Qiagen), as described before [5]. cDNA was diluted 1:20 before being used as a template in qPCR assays (SYBR ${ }^{\circledR}$ Green PCR Master Mix, Applied Biosystems). qPCR conditions were similar as described before [5] and glyceraldehyde-3-phosphate dehydrogenase (GAPDH) and hypoxanthine phosphoribosyltransferase (HPRT) were used as reference genes to normalize gene expression. Data from 4 separate experiments were factor corrected as stated in the "Statistics and factor correction" section below and tested for significance using a KruskalWallis test with Dunn's post hoc test. Primer pairs used are listed in Table 1.

\section{Western blots}

Cells were washed and collected with a cell scraper into $100 \mu \mathrm{L}$ of cold lysis buffer consisting of a suspension buffer (0.1 M NaCl, 0.01 M Tris-Hcl (pH 7.6), 1-mM Ethylenediaminetetraacetic acid (EDTA) with $1 \%$ Triton$\mathrm{x} 100)$ and protease inhibitors were added $(100-\mu \mathrm{g} / \mathrm{mL}$ phenylmethanesulfonylfluoride (PMSF)(Roche Diagnostics) and $0.5-\mu \mathrm{g} / \mathrm{mL}$ Leupeptin (Roche Diagnostics). Cells were vortexed and incubated for $5 \mathrm{~min}$ on ice. Subsequently, samples were spun at $11.7 \mathrm{k}$ rcf for $1 \mathrm{~min}$. Supernatant was taken off and stored at $-20{ }^{\circ} \mathrm{C}$ until further use. Protein concentrations were measured using a BCA kit (Pierce, Thermo Scientific), according to manufacturers descriptions. Proteins were mixed with $2 \mathrm{X}$ loading buffer (2X: $100 \mathrm{mM}$ Tris $\mathrm{pH}$ 6.8, $4 \%$ SDS, $20 \%$ glycerol, $0.2 \mathrm{M}$ dithiothreitol, and bromophenol blue), heated for $5 \mathrm{~min}$ at $95{ }^{\circ} \mathrm{C}$, and loaded on a $7.5 \%$ SDSPAGE reducing gel. After electrophoresis, proteins were blotted on Whatman Protran membranes (GE Healthcare) using a semi-dry Trans-Blot system (Biorad) for $60 \mathrm{~min}$. Blots were incubated with SuMi (50 mM Tris, $150 \mathrm{mM}$ $\mathrm{NaCl}, 0.25 \%$ gelatine and $0.5 \%$ Triton $\mathrm{X}-100, \mathrm{pH} 7.4$ ) for $10 \mathrm{~min}$ before they were incubated with primary antibodies at $4{ }^{\circ} \mathrm{C}$ overnight. Blots were subsequently washed 3 times in TBS-T (100 mM Tris-Hcl pH 7.4, $150 \mathrm{mM} \mathrm{NaCl}$ with $0.2 \%$ Tween-20), before secondary antibodies [IRdye 800 (1:2000) (LI-COR) and Dyelight Cy5 (1:4000) (Jackson 
Table 1 qPCR primer pairs of human GFAP isoforms

\begin{tabular}{|c|c|c|}
\hline Transcript & Forward primer & Reverse primer \\
\hline GFAP $\alpha$ endogenous & CCCACTCTGCTTTGACTGAGC & CСTTCTTCGGCCTTAGAGGG \\
\hline GFAP $\delta$ endogenous & GTGGTAAAGGTGGTGAGTCCTT & AGAGGCTGCTGCTTGCTC \\
\hline Vimentin & CGTACGTCAGCAATATGAAAGTGTG & TCAGAGAGGTCAGCAAACTTGGA \\
\hline Nestin & GATCTAAACAGGAAGGAAATCCAGG & TCTAGTGTCTCATGGCTCTGGTTTT \\
\hline$G F A P \alpha$ & CTTCTCCAACCTGCAGATTCG & CACGGTCTTCACCACGATGTT \\
\hline GFAP $\delta$ & CCGTGCAGACCTTCTCCAA & CGTATTGTGAGGCTTTTGAGATATCT \\
\hline GFAP & GTCAGTACAGCAGGGCCTCG & AGGAGCGCTGCAGTGTCACG \\
\hline$G F A P \beta$ & CGGGCATCGCCAGTCTAG & ATCCTGCTCTGGCTCTGCTC \\
\hline$G F A P \gamma$ & CTCAGAAGAGCCTGGACCCA & GGCTTCCAGCCTCAGGTTG \\
\hline GFAP $\zeta$ & GCACTGTGCACGTTCCCTG & GGTCCTGCCTCACATCACATC \\
\hline GFAP $\triangle E x 6$ & TGCGCGGCACGGATC & CACGGTCTTCACCACGATGTT \\
\hline GFAP $\triangle 135$ & TCTGCGCGGCACGGAGTA & GGGAATGGTGATCCGGTTCT \\
\hline GFAP $\triangle 164$ & GAGGCGGCCAGTTATTCCC & CACGGTCTTCACCACGATGTT \\
\hline GFAP $\triangle E x 7$ & GCGAGGAGAACCGAAACCAG & CTTCACCACGATGTTCCTCTTG \\
\hline
\end{tabular}

Endogenous GFAP $\alpha$ and GFAP $\delta$ primers are located in the $3^{\prime}$ UTR part, which is absent in the plasmid cDNA. The primer sequences used were published before [15]

GFAP glial fibrillary acidic protein

Immune Research), diluted in SuMi were incubated at room temperature for $1 \mathrm{~h}$. Blots were washed again 3 times in TBS-T before scanning with an Odyssey scanner (LICOR). GAPDH was used as a loading control.

\section{Immunocytochemistry}

To perform immunocytochemical staining, cells were cultured on uncoated glass coverslips, fixed with $4 \%$ Paraformaldehyde (PFA), washed in PBS, and incubated in SuMi buffer for $10 \mathrm{~min}$. Primary antibodies were diluted in SuMi and incubated at $4{ }^{\circ} \mathrm{C}$ on a shaker $\mathrm{O} / \mathrm{N}$. Cells were washed 3 times in PBS and, subsequently, incubated with secondary antibodies and Hoechst 33258 (1:1000 dilution) (Invitrogen) diluted in SuMi at RT for $1 \mathrm{~h}$. The antibodies used are listed in Table 2. All secondary antibodies were from Jackson Immune Research and diluted 1:1400 in SuMi. Cells were washed again in PBS, before the coverslips with cells were mounted on slides with Mowiol
[0.1 M Tris- $\mathrm{HCl} \mathrm{pH} 8.5,25 \%$ glycerol, $10 \%$ Mowiol (Calbiochem, Merck Millipore)]. The actin network was visualized with acti-stain Phalloidin 670 (Cytoskeleton inc; 1:1000 dilution). All fluorescent images were taken with a Leica SP5 confocal microscope (Leica) with a $63 x$ objective.

\section{Cell morphology measurements}

Phase contrast pictures were taken from the U251 cells transduced with GFAP isoforms and mCherry (control) on a Zeiss Axiovert 2000 with an Exi Aqua camera (Q Imaging, Surrey, Canada). Cell outlines were manually drawn using Image J. Area and perimeter were measured in square units. Form factor was calculated as $4 \pi \frac{\text { (Area) }}{{\text { (Perimeter })^{2}}^{2}}$, where perfectly round cells will have a form factor of 1 [43, 48]. Five independent experiments were performed with 40 cells analyzed per experiment. Data have been factor corrected for inter-experimental variation as stated

Table 2 Primary antibodies

\begin{tabular}{llll}
\hline Antibody & Manufacturer & Dilution & Cat \# \\
\hline Pan GFAP Dako & Dako & $1: 4000(1: 8000$ WB) & Z0334 \\
hGFAP $\delta$ & Manufactured in house (10-05-2001 Bleed) & $1: 1000(1: 1300$ WB) & - \\
GFAP c-term & Santa Cruz & $1: 4000($ WB $)$ & Sc-6170 \\
Vimentin & Chemicon & $1: 3000$ & AB5733 \\
GAPDH & Abcam & $1: 4000($ WB) & AB14247 \\
\hline
\end{tabular}

GFAP glial fibrillary acidic protein, WB western blot, $c$-term carboxy terminal, $h G F A P$ human GFAP, GAPDH glyceraldehyde-3-phosphate dehydrogenase 
below. A Kruskal-Wallis test was performed with Dunn's post hoc test to test for significance.

\section{Live cell imaging}

U343MG cells were imaged for $48 \mathrm{~h}$ using a Leica IR-BE (Leica Microsystems $\mathrm{GmbH}$ ) inverted wide field microscope at $37{ }^{\circ} \mathrm{C}$ in a custom built incubator containing $5 \%$ $\mathrm{CO}_{2}$. Phase contrast and fluorescence images were acquired with a 40x objective at 10 and $30 \mathrm{~min}$ time intervals during $48 \mathrm{~h}$. The single images were reconstructed and rendered into a time-lapse using Huygens software (Scientific Volume Imaging) and Image Pro Plus (Mediacybernetics).

\section{Fluorescent recovery after photobleaching (FRAP)}

FRAP analysis was performed on transiently transfected U251MG cells. During imaging the temperature was maintained at $37{ }^{\circ} \mathrm{C}$ in a humidified incubator chamber (OKO labs). Cells were analyzed $24 \mathrm{~h}$ after transfection. To monitor dynamics of GFAP in collapsed networks, we transfected the cells with GFAP $\delta$ in combination with either GFP-GFAP $\alpha$ or GFP-GFAP $\delta$. FRAP experiments were carried out on a SP5 Leica Confocal Microscope (Leica) with a $63 \mathrm{x}$ objective. The pinhole was set on $209.99 \mu \mathrm{m}$, and the scanning speed was at $400 \mathrm{~Hz}$ with a resolution of $512 \times 512$ pixels. Bar-shaped regions of interest (ROI) of $1.5 \mu \mathrm{m} \times 10 \mu \mathrm{m}$ were bleached with a 488-nm Argon laser (full laser power) until at least $50 \%$ of the fluorescence was bleached. Immediately after bleaching, a time-series of capturing 10 frames with a $30 \mathrm{~s}$ interval were made. Then, z-stacks were taken manually every $5 \mathrm{~min}$ up to $30 \mathrm{~min}$ after bleaching. To ensure that the bleached ROI did not drift out of focus, $\mathrm{z}$-stacks were made throughout the whole cell. Three ROIs were bleached per cell at different locations within the IF network. FRAP experiments were performed at different days in at least three separate experiments. This resulted in the following amount of ROIs measured: $33 \times \mathrm{GFAP} \alpha$ in a network, $30 \times$ GFAP $\delta$ in a network, $8 \times$ GFAP $\alpha$ in a collapse, and $8 \times$ GFAP $\delta$ in a collapse.

\section{FRAP analysis}

ROIs were positioned in post bleach pictures manually. Per time point, the position of the ROI was corrected for cell movement, and average fluorescence was measured using Image $\mathrm{J}$. The average fluorescence was plotted in time to obtain fluorescence recovery curves for every ROI. The half time was calculated by interpolating the time at $50 \%$ of the fluorescence of the maximum fluorescence at $30 \mathrm{~min}$. The immobile fraction was calculated by comparing the fluorescence in the bleached area after recovery $\left(F_{\infty}\right)$ with the fluorescence before bleaching $\left(F_{\mathrm{i}}\right)$ and just after bleaching $\left(F_{0}\right)$. The immobile percentage is defined as $\left(1-\left(F_{\infty}-F_{0}\right) /\left(F_{\mathrm{i}}-F_{0}\right)\right) \times 100$. For $F_{\infty}$, the average of the last three time points was used for analysis.

\section{Statistics and factor correction}

Data obtained from independent experiments were corrected with a factor correction program (version 10.5 2012) [49] when stated. Kruskal-Wallis, Kolmogorov-Smirnov, or Mann-Whitney tests were performed to test for significance. Differences were considered significant at $p<0.05$. All statistical tests were performed using Graphpad Prism 5 (version 5.04) (Graphpad Software Inc., La Jolla, CA, USA).

\section{Focal adhesion analysis}

To analyze focal adhesions, coverslips were coated with laminin in 24-wells plates. Cells were plated at 10,000 cells per well. After attaching for 2 days, cells were fixed with $4 \%$ PFA, stained with rabbit anti-phosphorylated-paxillin (pY118; Life Technologies), and counterstained with Hoechst and Phalloidin-488.

Fixed and immunostained samples were imaged on an inverted microscope (Zeiss Axiovert 200) with a Confocal Spinning-disk Unit (Yokogawa CSU X-1) and an emCCD camera (Andor iXon 897). Excitation was accurately controlled by $405 \mathrm{~nm}$ (Crystalasers), $514 \mathrm{~nm}$ (Cobolt), and $642 \mathrm{~nm}$ (Spectra Physics) lasers through an acousto-optic tunable filter (AA Optoelectronics) coupled into the CSU with a polarization-maintaining optical fiber. Images were acquired with Andor IQ 2 software, and further processing and analysis were performed in specifically designed software (Matlab, Mathworks).

Focal adhesions were automatically detected from the 642-nm fluorescence images. Focal adhesion size could be at least $0.4 \times 0.4 \mu \mathrm{m}$ and at most $4 \times 4 \mu \mathrm{m}$. In an image of $512 \times 512$ pixels low pass frequency with a cut-off at 2 pixels filtering removed large features. With a subsequent threshold of 3 times the standard deviation of the image, we obtained and characterized the focal adhesions. Focal adhesion size differences were tested using a 2-tailed Kolmogorov-Smirnov test. Differences were considered significant if $p<0.05$. Per condition, a different amount of cells and focal adhesion were measured, but at least exceeded 30 different cells and a total of more than 700 focal adhesions. 


\section{Results}

\section{GFAP $\delta$ perturbs the GFAP network in astrocytes}

Cellular models for studying GFAP isoform function were established by expression of GFAP isoforms in U251 cells and primary human astrocytes. The mRNAs of the different isoforms were highly expressed in the transduced U251 cell lines (Sup. Fig. 1a, b) and primary human astrocytes (Sup. Fig. 1d, e). Western blot analysis showed a clear expression of either GFAP $\alpha$ or $\delta$ (Sup. Fig. 1c), while the control (Ctrl) only showed a band with the pan GFAP antibody, representing endogenous GFAP $\alpha$. The endogenous expression of the other GFAP isoforms was determined with $\mathrm{qPCR}$ and is presented as a percentage of the canonical GFAP $\alpha$ expression. GFAP $\alpha$ and GFAP $\delta$ were the most abundant isoforms expressed, followed by GFAPк. Other isoforms were expressed at a very low level (Sup. Fig. 1f).

First, we confirmed whether GFAP $\delta$-induced cytoplasmic collapses of GFAP also occurred in the transduced U251 cells and primary human astrocytes, as we have shown before in SW13 human adrenal carcinoma cells and U343 astrocytoma cells [5, 17]. We investigated the IF network morphology by immunostainings for GFAP, and we observed that the different GFAP isoforms gave similar results in both the primary human astrocytes (Fig. 1a) and the human U251 astrocytoma cells (Fig. 1b). The endogenous GFAP network was stained in the control condition, in which cells were transduced with mCherry. The GFAP network was present throughout the cytoplasm up to close proximity of the cell periphery, which is visualized by actin staining. Expression of recombinant GFAP $\alpha$ in human astrocytes, or in U251 cells, resulted in a GFAP network which was morphologically similar to astrocytic IF networks, indicating that the recombinant GFAP $\alpha$ was incorporated into the endogenous IF network of the cells. In contrast, expression of GFAP $\delta$ led to a collapse of the GFAP network mostly in a perinuclear fashion (Fig. 1a, b). This perturbing effect of GFAP $\delta$ on the GFAP network in these cells is concentration dependent and is a gradual process (data not shown), as has also been described before $[16,17]$.

\section{Vimentin and nestin co-collapse with GFAP $\delta$, while actin and microtubules stay intact}

To assess whether GFAP $\delta$ induces a collapse of the complete cytoplasmic IF network, we also studied the distribution of vimentin (Fig. 2a) and nestin (Fig. 2b), which were both present in the IF network in primary human astrocytes. Transduction with GFAP $\alpha$ had no effect on the intracellular location of these proteins, but transduction with GFAP $\delta$ led to a condensation of vimentin and nestin, mostly around the nucleus. The same effect was observed in the U251 cell line (not shown). The actin and microtubule cytoskeletal networks did not co-collapse with the IF network upon GFAP $\delta$ expression (Fig. 2a, b, Sup. Fig. 2a, b). The staining intensity of actin was very variable between cells and between conditions, but the overall morphology of the actin network showed no actin collapse induced by GFAP $\delta$.

To examine whether the additional expression of GFAP $\alpha$ or GFAP $\delta$ would lead to effects on transcription of other IFs, we analyzed the change in mRNA expression of vimentin, nestin, and endogenous GFAP $\alpha$ and GFAP $\delta$ in U251 cells using quantitative PCR. GFAP $\alpha$ mRNA (Sup. Fig. 3a), GFAP $\delta$ mRNA (Sup. Fig. 3b), vimentin mRNA (Sup. Fig. 3d), and vimentin protein (Sup. Fig. 3e) levels were not significantly changed due to an increase in either GFAP $\alpha$ or GFAP $\delta$. However, we noticed a small but significant upregulation of nestin transcript in GFAP $\alpha$ expressing cells $(p=0.03)$ (Sup. Fig. 3c).

\section{GFP tagged GFAP incorporates into the endogenous IF network}

Next, we assessed the dynamic properties of GFAP isoforms using N-terminally GFP tagged GFAP fusion proteins for live cell imaging. The transduced cells express GFP-labeled GFAP isoforms, and thereby, transduced cells can be directly identified based on the reporter GFP. Both GFP-GFAP $\alpha$ and GFP-GFAP $\delta$ did incorporate into the endogenous IF network of U251 cells (Sup. Fig. 4a, b). Since a high expression of tagged GFAP also led to a collapse of the network, a relatively low expression was needed to image a non-collapsed network, which was established by analysis $24 \mathrm{~h}$ after transient transfection using U251 cells for a reasonable transfection efficiency. $24 \mathrm{~h}$ after transfection, the GFP-GFAP $\alpha$ transfected cells showed a spread out network (Sup. Fig. 5a), and GFP-GFAP $\delta$ expressing cells showed a mixture of cells with either a spread out network (Sup. Fig. 5b) or a collapsed IF network (Sup. Fig. 5c). The endogenous IF network is visualized by the vimentin staining. About $30 \%$ of the GFP-GFAP $\delta$ expressing cells in our cell culture condition showed a collapse at this time point, although the exact percentage varied between experiments and was dependent on the transfection efficiency. 
Fig. 1 GFAP isoform

expression in primary human astrocytes and U251

astrocytoma cells. a Human primary astrocytes transduced with GFAP $\alpha$, GFAP $\delta$, or mCherry (control). Cells were stained with pan GFAP Dako antibody (GFAP) together with phalloidin (Actin) and Hoechst (Hst). The reporter showed in the middle panel which cells were transduced cells, and these are additionally highlighted in the right panel with red stars. Expression of GFAP $\alpha$ resulted in a dense GFAP network, which was spread throughout the whole cell. Expression of GFAP $\delta$ showed a drastic redistribution of the GFAP network, which collapsed in a perinuclear fashion. b Human U251 astrocytoma cells

transduced with GFAP $\alpha$, GFAP $\delta$, or mCherry (control) also showed a collapse of the GFAP network in GFAP $\delta$ transduced cells only. In this panel, all cells were transduced, as these were stably transfected cell lines. A close up of the collapsed network is shown in the lowest panel. Scale bars represent $20 \mu \mathrm{m}$
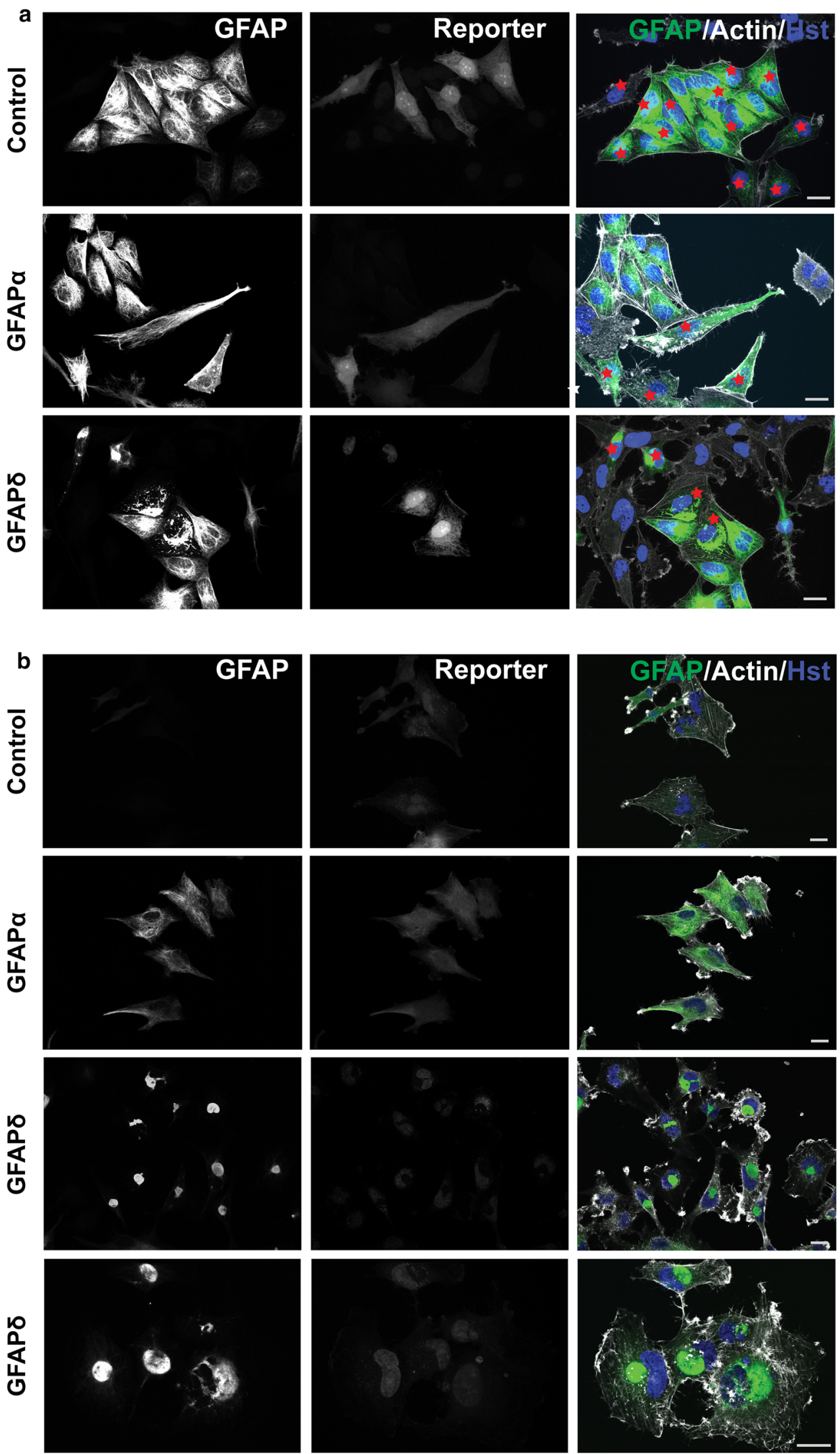
Fig. 2 GFAP $\delta$ collapses the whole IF network. a Primary human astrocytes transduced with GFAP $\alpha$, GFAP $\delta$, or control plasmid stained for vimentin and actin or $\mathbf{b}$ nestin and actin. Astrocytes expressing ectopic GFAP $\alpha$ or mCherry had a network that was spread throughout the whole cell while GFAP $\delta$ expressing cells showed a perinuclear collapse of both vimentin and nestin in cells positive for the reporter only. GFAP $\delta$ transduced cells with relative low expression, as seen by lower reporter expression, do not show a collapsed IF network yet. Scale bar represents $20 \mu \mathrm{m}$
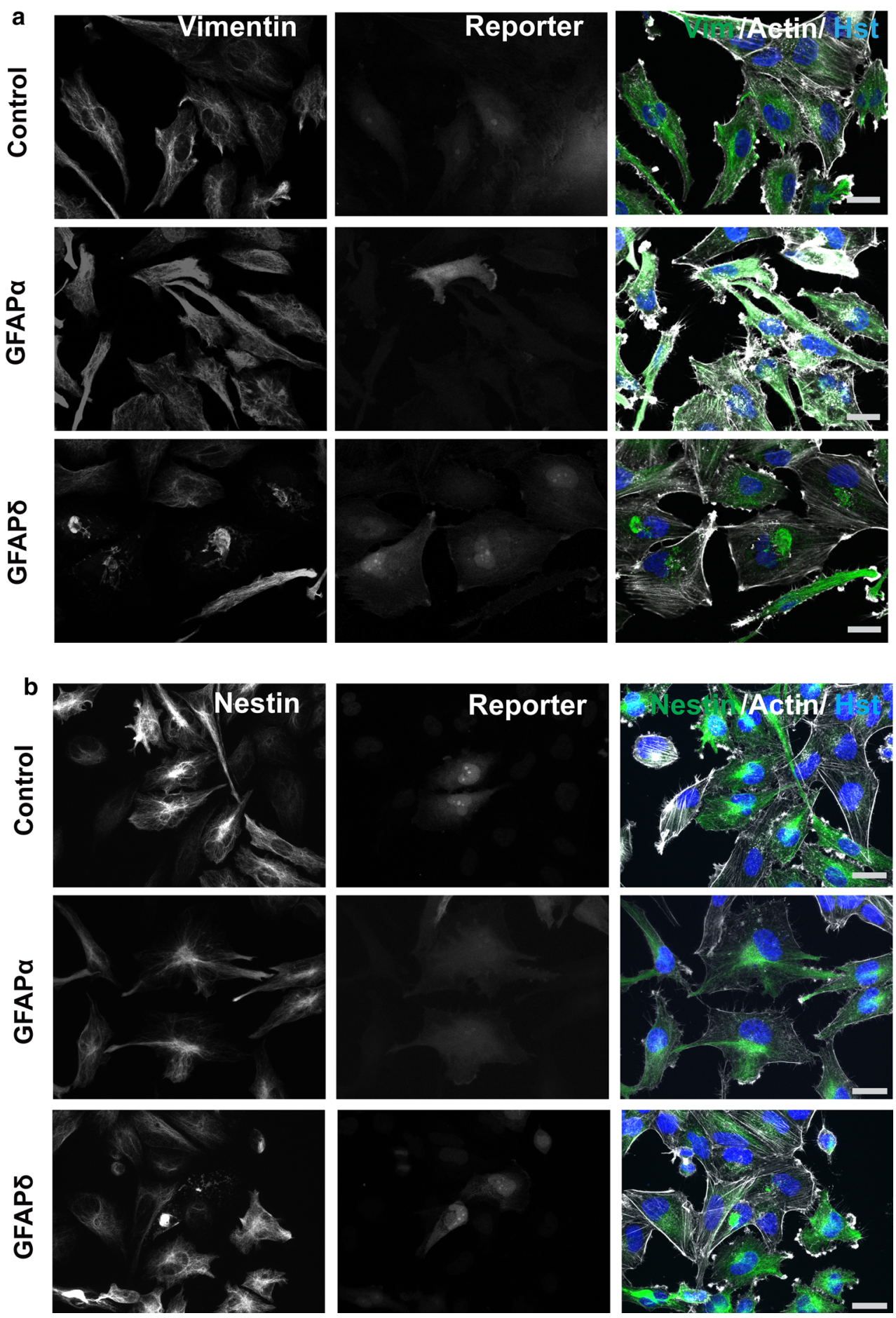

Live cell imaging of the GFAP $\delta$ dynamically shows the collapse of the network

To visualize the dynamics of the collapsing network over time, U343MG astrocytoma cells transfected with GFPGFAP $\delta$ were imaged for $48 \mathrm{~h}$, starting $4 \mathrm{~h}$ after transfection. U343MG cells were used here, since they are less motile than U251MG cells, which enabled us to image the
IF network for a long period of time. First, GFP-GFAP $\delta$ was distributed throughout the IF network in the whole cell (arrow in Fig. 3a $t=12 \mathrm{~h}$ ). GFP-GFAP $\delta$ started to condensate around the nucleus, as the expression of GFPGFAP $\delta$ increased over time (Fig. $3 \mathrm{a}$ and Sup. Movies 1 and 2). Sometimes small aggregates or condensations were seen, which joined the already collapsed GFAP proteins (arrowheads Fig. 3a $t=30$ and Sup. Movies 1 and 2). 

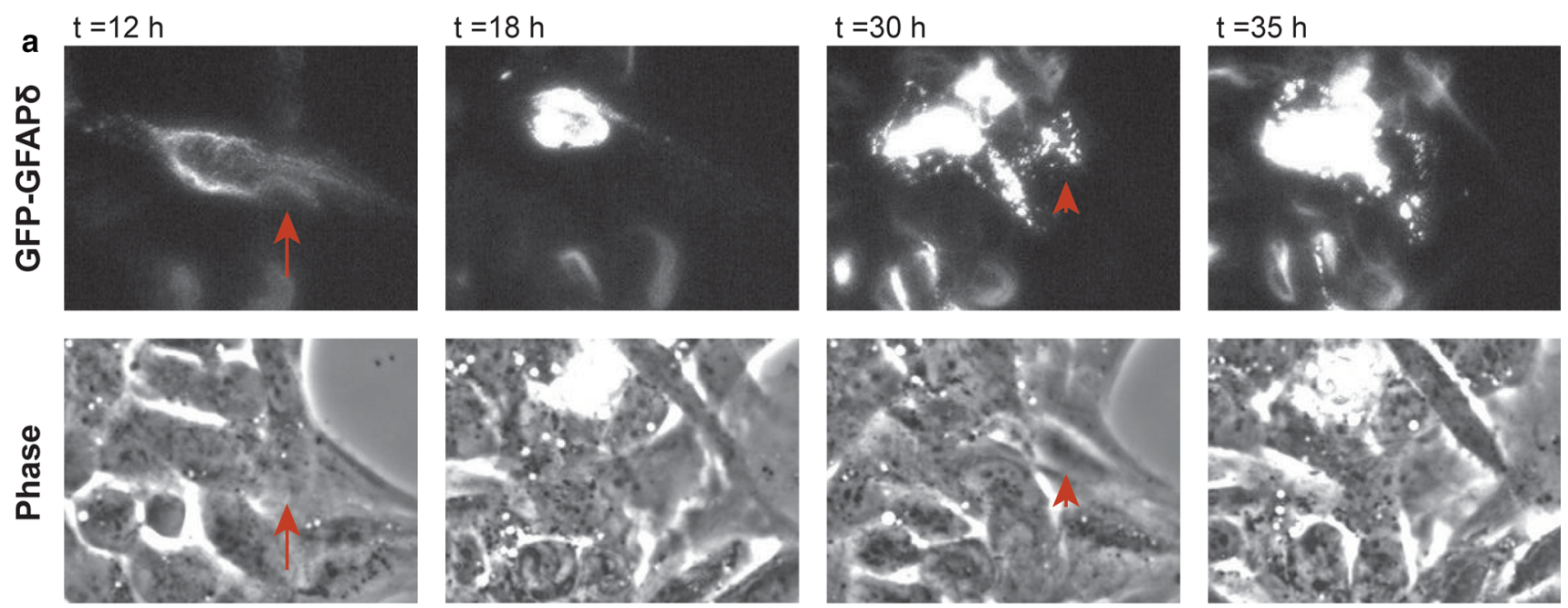

b
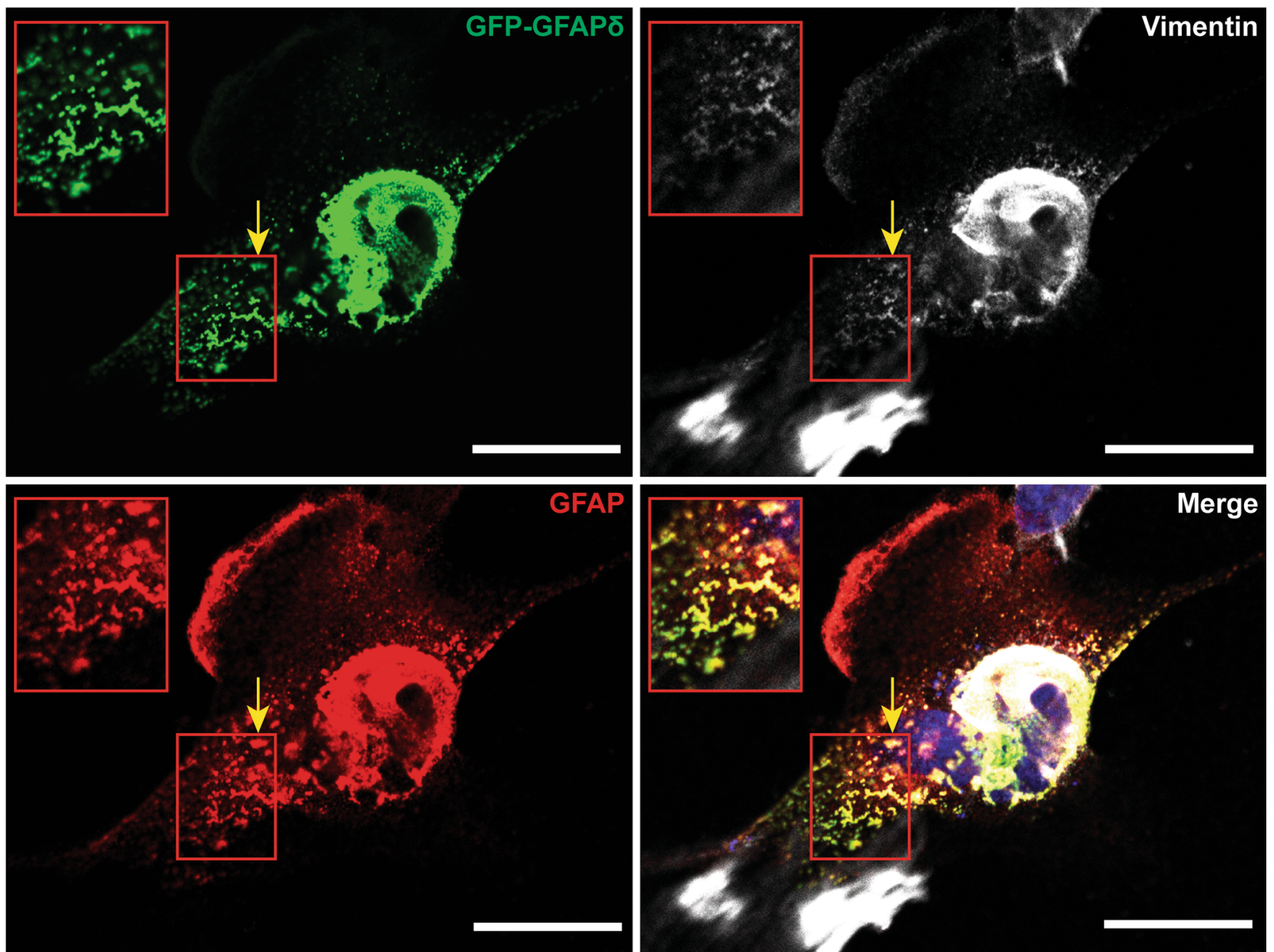

Fig. 3 Collapse of the IF network due to high GFP-GFAP $\delta$ expression. a Stills from a representative live cell imaging experiment. U343MG cells were transfected with GFP-GFAP $\delta$ and imaged for $48 \mathrm{~h}$. The GFP-GFAP $\delta$ was initially incorporated into the IF network (arrows at $t=12 \mathrm{~h}$ ), but as the amount of GFP-GFAP $\delta$ increased over time, it eventually caused a collapse of the network

( $t=18 \mathrm{~h}$ ). During the process of collapsing, thicker and shorter filamentous structures are visible in the cell, which are moving into the direction of the collapsed network (arrowheads in $t=30 \mathrm{~h}$ ). b These small filaments sometimes co-localized with vimentin in U251MG cells as well (yellow arrow). Scale bars represent $20 \mu \mathrm{m}$. See also supplemental Movie 1 and 2 
During and after the process of the accumulation, cells were still migrating, and the collapsed IF network was a motile structure in both stationary and moving cells. These experiments showed that GFP-GFAP $\delta$, in small amounts, is incorporated into the endogenous IF network before it causes a collapse of the IF network. Images from fixed cells stained for GFP, GFAP, and vimentin showed that the squiggles (short filaments) of GFP-GFAP $\delta$ sometimes colocalized with vimentin and were not part of larger filaments (Fig. 3b, arrow).

\section{Dynamic properties of GFP-GFAP $\alpha$ are different from GFP-GFAP $\delta$}

To assess the dynamic properties of GFAP $\alpha$ and GFAP $\delta$, FRAP experiments were performed on U251 astrocytoma cells in which small boxed regions of fluorescent cells were photobleached, and recovery of fluorescence was measured over time. Cells were transfected with the GFP-GFAP isoforms, and the FRAP analysis was started $24 \mathrm{~h}$ later. Cells with non-collapsed and collapsed networks were measured and analyzed separately. Regions of fluorescent GFAP networks were bleached, and the fluorescence recovery was imaged up to $30 \mathrm{~min}$ after bleaching. A typical example is shown in Fig. 4a. The median of all FRAP recovery experiments for GFAP $\alpha$ and GFAP $\delta$ in an extended network and GFAP $\delta$ in a collapsed network are shown in Fig. $4 \mathrm{~d}$. The half time $t_{1 / 2}$ (the time needed to recover to $50 \%$ of the final fluorescence) and the immobile fraction (the percentage of fluorescence which is not recovered) were calculated. The median $t_{1 / 2}$ value of GFAP $\delta$ in extended, non-collapsed networks was $2.3 \mathrm{~min}$, and this was significantly $(p<0.05)$ longer than the median $t_{1 / 2}$ of GFAP $\alpha$, which was $1.1 \mathrm{~min}$ (Fig. 4b). Since high GFAP $\delta$ expression leads to a collapse of the IF network, we next investigated the dynamic properties of GFAP $\delta$ in a collapsed network. Although not significant, there was a clear trend visible that GFAP $\delta$ had a longer $t^{1 / 2}$ $($ median $=3.8 \mathrm{~min})$ when in a collapsed network compared with GFAP $\delta$ in a spread out network (Fig. 4b), indicating a slower on/off rate from the IF network. We also calculated the immobile fraction of the GFP-GFAPs, which is the percentage of fluorescence that did not recover from the FRAP curves. We observed that the immobile fraction did not significantly differ between GFAP $\alpha$ (median $=40.3 \%)$ or GFAP $\delta$ in extended network (median $=49.1 \%)$. There was, however, a significant difference between the immobile fraction of GFAP $\delta$ when the majority of the GFAP was in a collapsed network (median $=56.4 \%)$ compared with the immobile fraction of GFAP $\alpha$ and GFAP $\delta$ when GFAP was in a spread out network (Fig. 4c).
To assess whether the change in dynamic properties between GFAP $\delta$ when in a network and when it has collapsed was due to the collapse of the network and not GFAP $\delta$ itself, we performed experiments in which we also measured the dynamics of GFAP $\alpha$ in a collapsed network. To study this, we transfected cells with untagged GFAP $\delta$ to induce the collapse, and co-transfected either GFP-GFAP $\alpha$ or GFP-GFAP $\delta$ to visualize the fluorescent isoform dynamics. Both GFP-GFAP $\alpha$ (Sup. Fig. 5a) and GFPGFAP $\delta$ (Sup. Fig. 5b) were incorporated into the collapse as can be seen by staining for vimentin, which is highly expressed in U251 cells and shows the endogenous IF network. A representative example of a bleached collapsed network and the subsequent recovery is shown in Fig. 5a. The median $t_{1 / 2}$ for GFAP $\alpha$ (4.4 min) and GFAP $\delta$ (5.5 min) did not differ significantly $(p=0.8)$ (Fig. 5b). The $t_{1 / 2}$ measured for GFAP $\alpha$ was remarkably increased due to the collapsed network (Fig. 5b). The fluorescence had not yet reached plateau after $30 \mathrm{~min}$ of recovery. Taken together, this indicates that GFAP $\alpha$ and GFAP $\delta$ have different exchange dynamics (as measured by $t_{1 / 2}$ ) and the dynamics show a trend for higher $t_{1 / 2}$ when the IF network is collapsed.

\section{A collapsed IF network changes cell morphology}

Next, we aimed at defining whether the IF network collapse and changes in dynamics also result in a change in morphology, since IF expression has been linked to cell morphology [40, 43]. Morphological parameters of living U251 cells expressing different GFAP isoforms were determined by measuring the cell surface area and the perimeter. From these parameters, we calculated the form factor, as described in the methods section. Forty cells were analyzed per experiment in five independent experiments. GFAP $\delta$ expression caused the cells to become rounder $(0.56 \pm 0.006$; mean $\pm \mathrm{SEM})$ in comparison with the control $(0.49 \pm 0.005, p=0.009)$ (Fig. 6a). We also observed significant differences in perimeter (Fig. 6b) and area (Fig. 6c) between cells expressing GFAP $\delta$ and GFAP $\alpha$.

To assess whether the morphological changes we observed were due to changes in cell-extracellular matrix interaction, the sizes of focal adhesions were assessed by phosphorylated paxillin stainings in cells plated on a laminin substrate. In both GFAP $\alpha$ and GFAP $\delta$ expressing cells, the size of the focal adhesion was increased (mCherry: $1.13 \mu \mathrm{m}^{2} \pm 0.02$; GFAP $\alpha$ : $1.34 \mu^{2} \pm 0.03$; GFAP $\delta: ~ 1.37 \mu \mathrm{m}^{2} \pm 0.03$ (Fig. 6e, f). There was, however, no transcriptional regulation of the main lamininbinding integrins expressed in these cells (data not shown). 

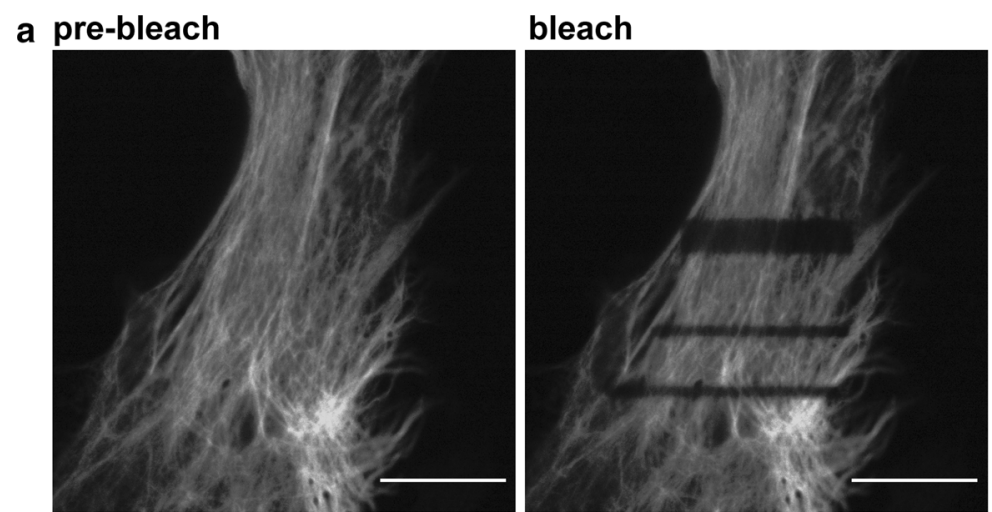

$t=30 s$

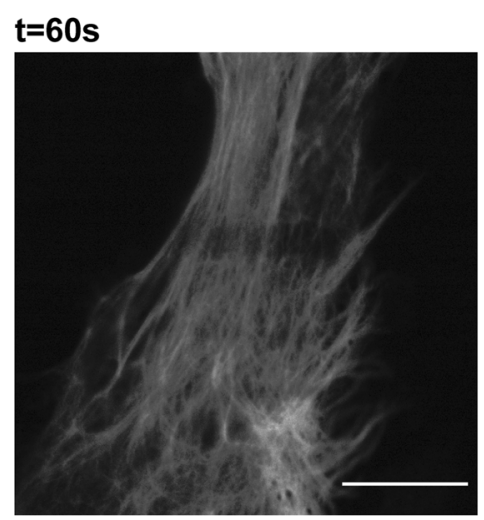

$t=90 s$
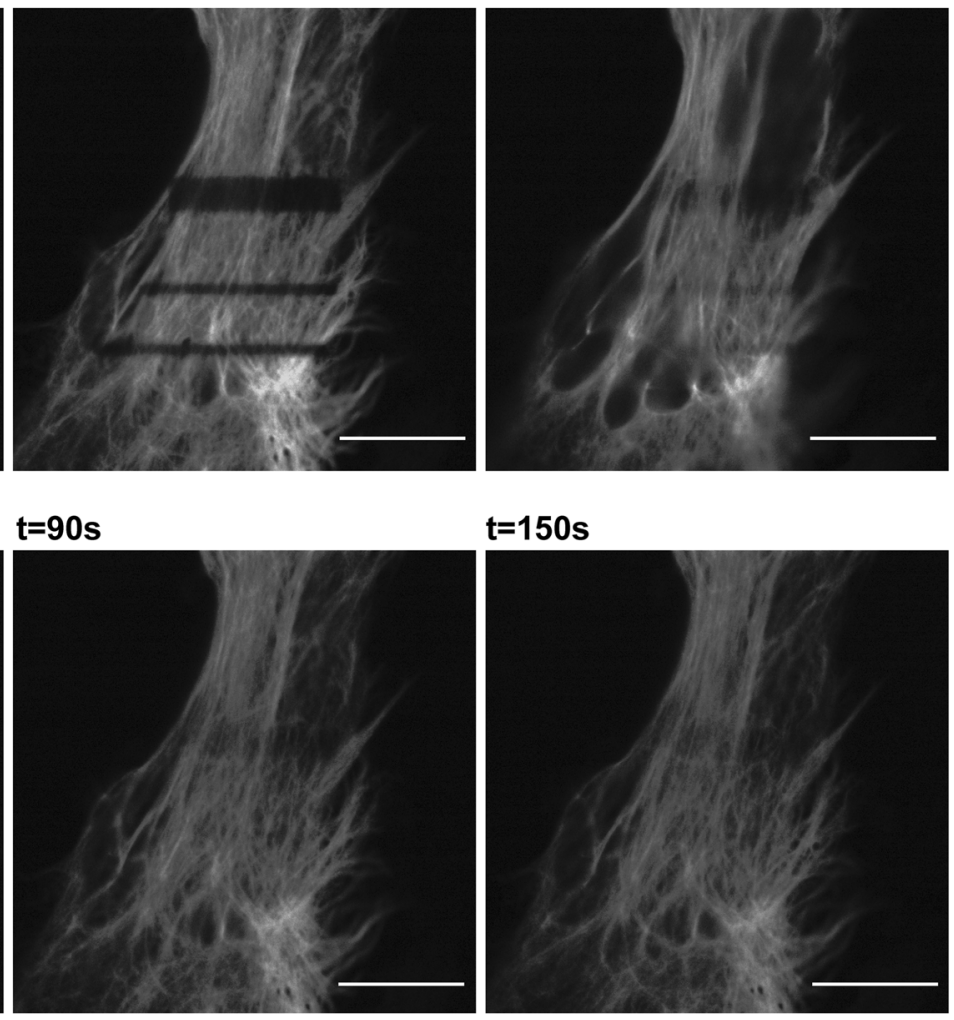

$t=150 s$
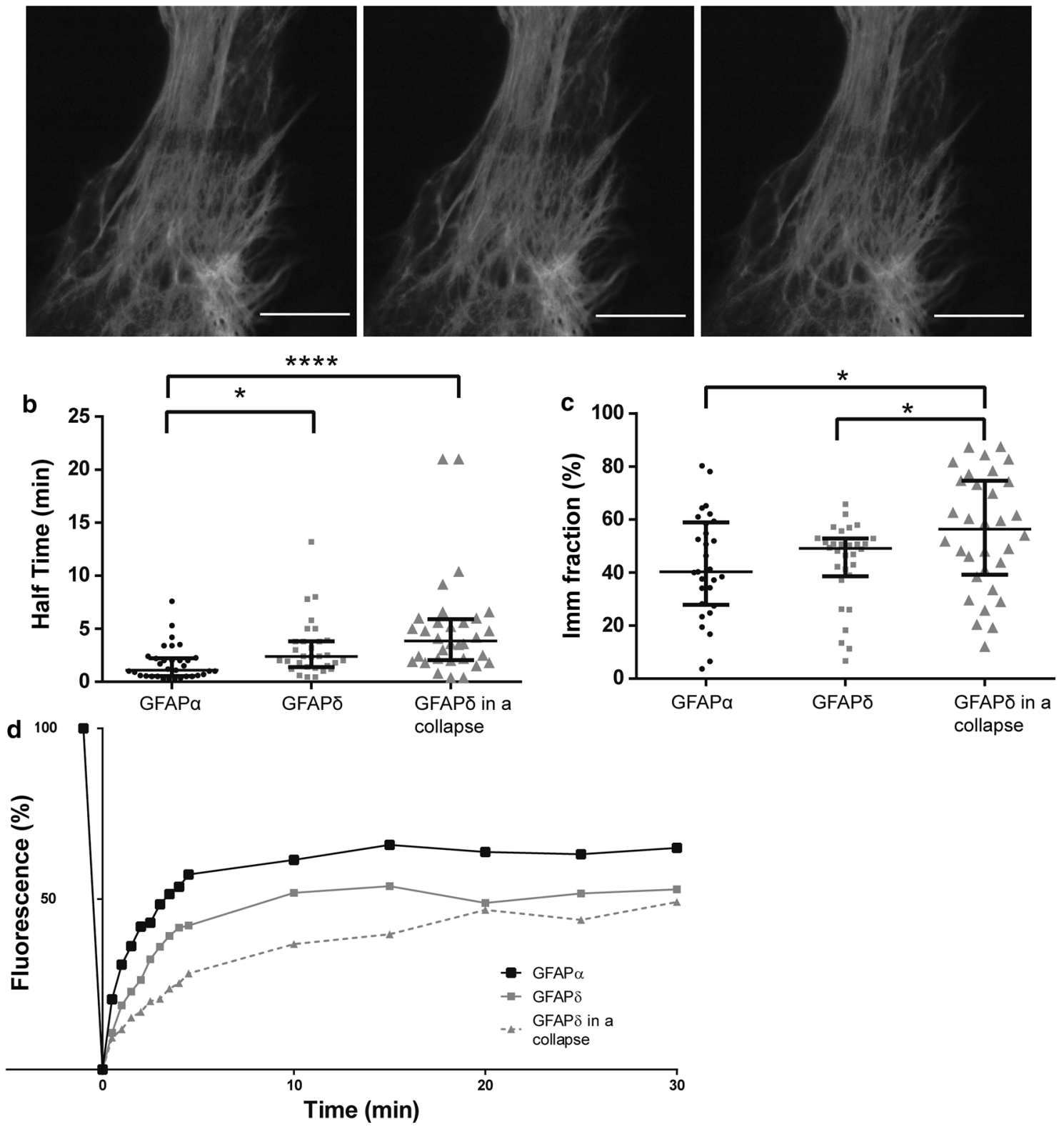
4Fig. 4 Different dynamics between GFAP $\alpha$ and GFAP $\delta$. a FRAP experiments consisted of bleaching ROI and measuring the fluorescence recovery up to $30 \mathrm{~min}$ after the bleach in U251MG cells. Within $150 \mathrm{~s}$, most of the fluorescence was recovered, but recovery was never complete. b FRAP experiments were performed for GFAP $\alpha$, GFAP $\delta$, and GFAP $\delta$ in a collapsed network, and half times were calculated. There is a significant difference in half time between GFAP $\alpha \quad($ median $=1.1 \mathrm{~min})$ and GFAP $\delta \quad($ median $=2.3 \mathrm{~min})$ $(p<0.05 ; n=33, n=30)$, and between GFAP $\alpha$ and GFAP $\delta$ in a collapsed network (median $=3.8 \mathrm{~min})(p=0.000 ; n=32)$. There was no significant difference in the half time of GFAP $\delta$ in spread out or collapsed network, although there was a trend that a collapse decreased the half time of GFAP $\delta$. $\mathbf{c}$ The immobile fractions were not significantly different between GFAP $\alpha(40.2 \%)$, GFAP $\delta(49.1 \%)$ ( $p=0.7 ; n=29$ and $n=30$ ). GFAP $\delta$ in a collapse did have a significantly different immobile fraction $(56.3 \% ; n=32)$ compared with $\operatorname{GFAP} \alpha(p=0.03)$ and $\operatorname{GFAP} \delta(p=0.04)$ in a network. Graphs $\mathbf{b}$ and $\mathbf{c}$ show median values with interquartile range. $\mathbf{d}$ Medians of FRAP curves for GFAP $\alpha$, GFAP $\delta$ and GFAP $\delta$ in a collapse show the recovery after bleaching. Non-parametric tests were performed on the data extracted from the FRAP measurements, so non-overlapping curves do not equal significant differences in this graph

\section{GFAP overexpression does not affect cell motility or cell proliferation}

Focal adhesions are tightly regulated during cell migration, and GFAP has been linked to in vitro migration by others $[4,43]$. To check for changes in cell motility, we analyzed single cell motility and scratch wound healing speed. Single cell motility assays were performed on U251 cells expressing GFAP $\alpha$, GFAP $\delta$, or mCherry. Cells were seeded on PLL coated glass coverslips, and thirty cells were analyzed per experiment in 3 independent experiments. There were no statistically significant differences in average velocity between U251 cells expressing GFAP $\delta$ $(0.53 \mu \mathrm{m} / \mathrm{min} \pm 0.09)$, GFAP $\alpha(0.44 \mu \mathrm{m} / \mathrm{min} \pm 0.08)$, or control $(0.50 \mu \mathrm{m} / \mathrm{min} \pm 0.02)(p=0.9)$ (Fig. 7a). Similar results were found in a wound healing assay where a monolayer of cells was scratched and the wound healing speed was measured over time (Fig. $7 \mathrm{~g}$ ). Wound healing speed of U251 cells expressing GFAP $\alpha(52.9 \% \pm 9.3)$, $\operatorname{GFAP} \delta(54.7 \% \pm 6.2)$, or the control $(50 \% \pm 7.3)$ was not different at $12.5 \mathrm{~h}(p=0.7)$. To study the effects of GFAP isoform expression on primary cell motility instead of on tumor cells, single cell motility assays were also done on primary human astrocytes. Again, we found no statistically significant difference between cell motility of cells expressing GFAP $\alpha(0.39 \pm 0.03)$, GFAP $\delta(0.37 \pm 0.02)$, and control cells $(0.43 \pm 0.009)(p=0.15)$ (Fig. 7b).

Since GFAP $\delta$ is highly expressed in proliferating astrocytes, i.e., neurogenic astrocytes [7, 8] and astrocytoma cells $[12,14]$, we determined the effect of GFAP $\delta$ expression on proliferation by performing a 3-(4,5Dimethylthiazol-2-yl)-2,5-diphenyltetrazolium bromide (MTT) assay [47]. We observed no significant difference between proliferation of GFAP $\delta(153 \% \pm 9.2)$, GFAP $\alpha$ $(180 \% \pm 19.8)$, and control (mCherry) $(156 \% \pm 5.3)$ $(p=0.56)$ over a period of $48 \mathrm{~h}$ in U251 cells (Fig. 7c). The MTT assay in primary astrocytes also did not show significant differences between GFAP $\alpha(146 \% \pm 3.8)$, GFAP $\delta(139 \% \pm 12.5)$, and control $(146 \% \pm 14.7)$ $(p=0.56)$ (Fig. 7d). To confirm these results, proliferation was also assessed by staining for the proliferation marker Phospho histone H3 (PHH3). U251 cells transduced with the GFAP isoforms were plated, fixed $48 \mathrm{~h}$ later, and stained for PHH3 (Fig. 7e). We observed no significant difference $(p=0.21)$ in the percentage of $\mathrm{PHH} 3$ positive cells between GFAP $\alpha \quad(7.3 \% \pm 1.1), \quad$ GFAP $\delta$ $(5.4 \% \pm 0.4)$, and control $(5.6 \% \pm 0.4)$. PHH3 staining in primary astrocytes did, however, show a significant difference between GFAP $\alpha(6.1 \% \pm 0.3)$ and GFAP $\delta$ $(3.4 \% \pm 0.2)(p=0.04)$ (Fig. 7f). Taken together, these data show that GFAP $\delta$ expression did not alter cell proliferation or motility, while GFAP $\alpha$ led to a slightly higher proliferation rate compared with GFAP $\delta$.

\section{Discussion}

Astrocytes and astrocytoma cells tightly regulate the expression of at least 10 different GFAP isoforms [6]. GFAP $\alpha$ and GFAP $\delta$ are the two most highly expressed isoforms. The functional consequences of changes in the IF network in astrocytes and astrocytoma cells are still elusive. In this study, we have investigated the effect of GFAP $\delta$ on cell proliferation, migration, motility, and shape but also the intracellular effects on IF network dynamics. We here show that GFAP $\alpha$ and GFAP $\delta$ have different intrinsic dynamic properties, but that expression of GFAP $\delta$ does not affect cell proliferation or migration when there is a collapse of the IF network.

\section{Dynamic properties}

GFAP $\delta$ is assembly compromised by itself [16] and causes a collapse of the whole IF network. We here show that even before a collapse, GFAP $\delta$ changes the dynamics of the the IF network. Dynamic properties of IF proteins differ between IF family members [50-53]. These differences are likely due to phosphorylation or structural properties that affect the assembly. The latter is for instance reflected in higher FRAP recovery half time values by the nuclear lamins ( $140 \mathrm{~min})[53,54]$, which forms IgG-like folds during assembly [55]. In contrast, GFAP and vimentin, which are both located in the cytoplasm, have half times between 1 and $5 \min$ [51, 52]. In this study, we showed that GFAP $\delta$ incorporates and dissociates slower from an IF 
a Pre bleach

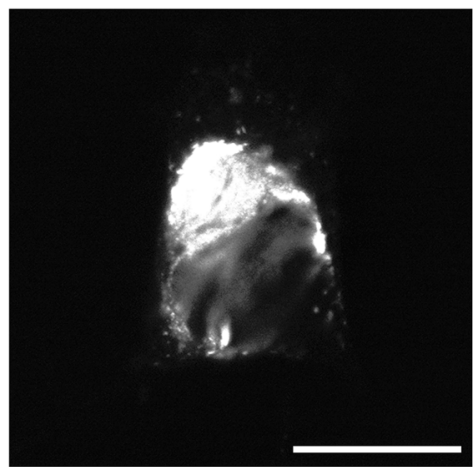

$\mathrm{t}=90 \mathrm{~s}$

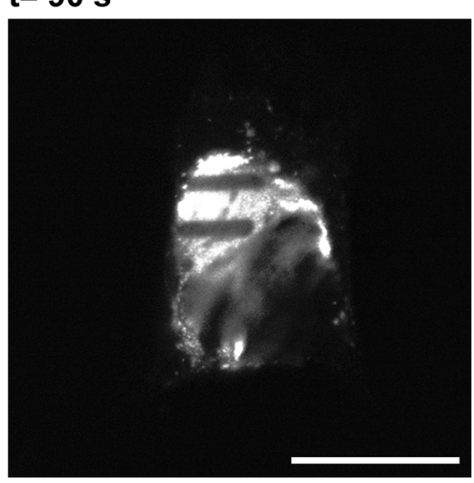

\section{Bleach}

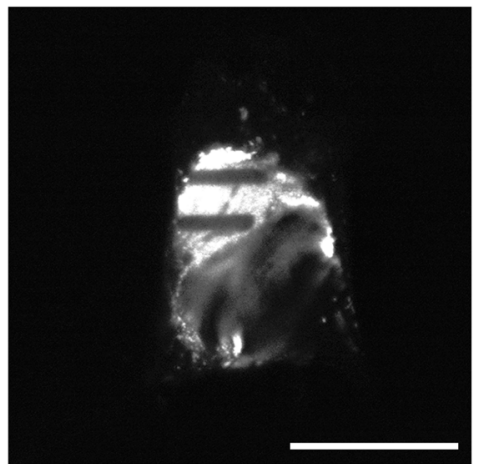

$\mathrm{t}=5 \mathrm{~min}$

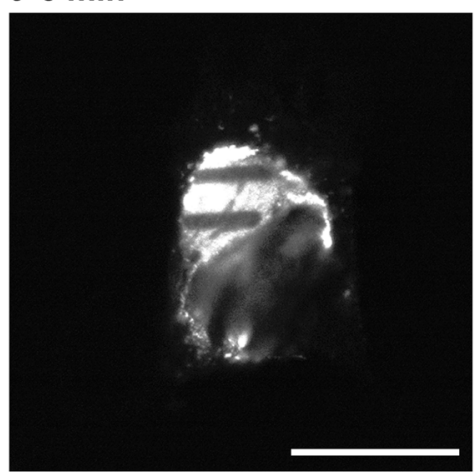

\section{$t=30 s$}

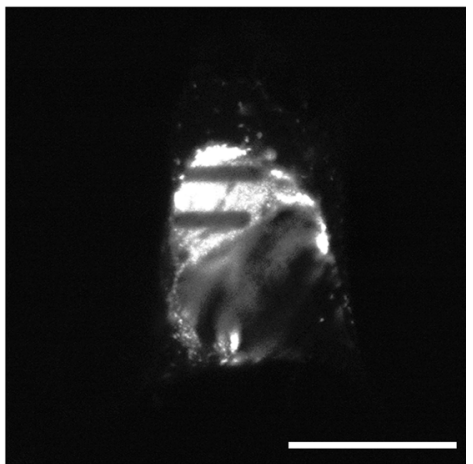

$t=30 \min$

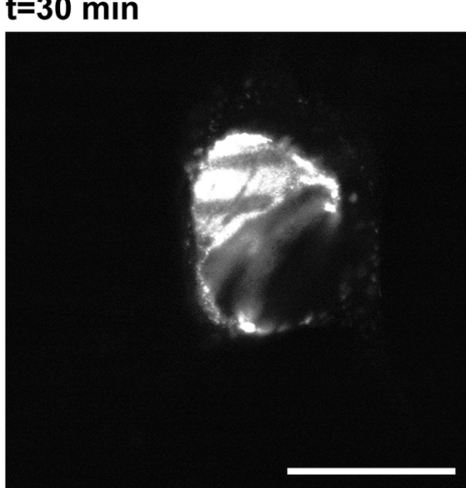

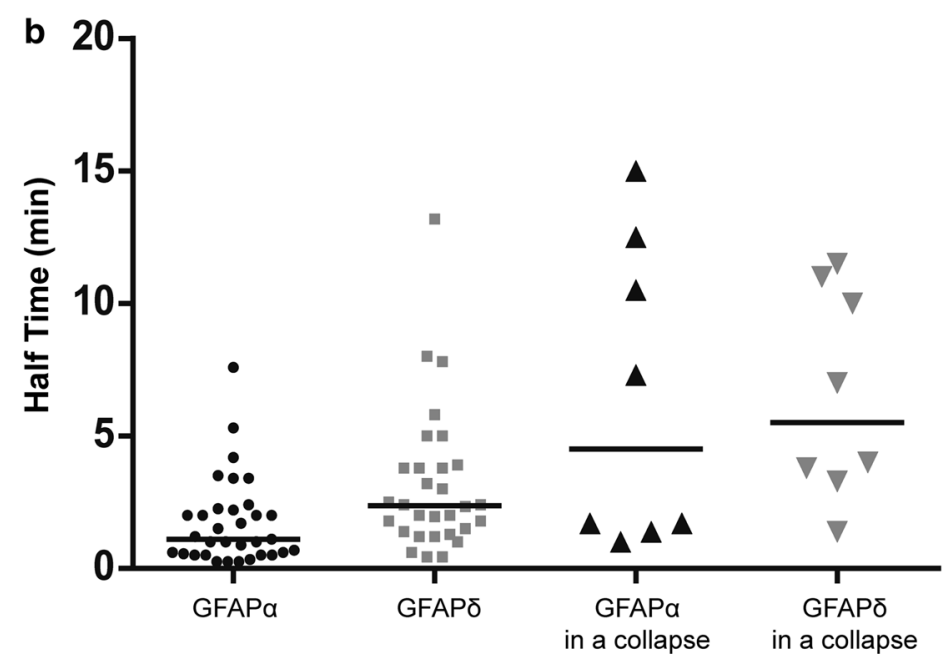

Fig. 5 Dynamics of GFAP isoforms in a collapsed IF network. a A representative still of a FRAP experiment on U251MG cells with a collapsed IF network. ROIs were bleached and the fluorescence recovery was measured for up to $35 \mathrm{~min}$. Even after $30 \mathrm{~min}$, the bleach area was still clearly visible. b Half times were calculated as described in the materials and methods section. There were no

network than GFAP $\alpha$. Since the C-terminal tail is the only difference between GFAP $\alpha$ and GFAP $\delta$, the differences in dynamics must be due to this specific sequence. IF protein motility and exchange are mediated through interactions with microtubules and actin to regulate transport [50], and IF protein phosphorylation to regulate filament stability significant differences between the half time of GFAP $\alpha$ in a collapse $($ median $=4.5 \mathrm{~min})$ or GFAP $\delta$ in a collapse $($ median $=5.5 \mathrm{~min})$ $(p=0.8 ; n=8)$. There was a clear trend showing that a collapse caused a longer half time (4.5 vs. $1.1 \mathrm{~min}$ for GFAP $\alpha$ and 5.5 vs. 2.3 min for GFAP $\delta$ ) of the GFAP isoforms

$[25,56,57]$. In the part of the C-terminus, where GFAP $\alpha$ and GFAP $\delta$ differ, the same amount of putative phosphorylation sites are present (7 residues). However, the position of these residues is different, possibly leading to a different availability of phosphorylatable residues in the protein tertiary structure. In the tail of GFAP $\delta$ is a coil $2 B$ 
binding site, which lacks in the GFAP $\alpha$ tail [16]. It has been proposed by Nielsen and Jorgensen [16] that this domain results in a gain of coiled-coil binding activity of GFAP $\delta$, which might explain the slower dissociation of GFAP $\delta$ from an IF network. Earlier experiments have shown that ablation of the whole C-terminal tail of IF type III proteins inhibits IF assembly [38, 58], but phosphorylation of vimentin at the C-terminal side did not affect its assembly [59]. Mutant GFAP isoforms, with mutated phosphorylation sites, will help to elucidate the effects of GFAP phosphorylation on network dynamics.

\section{Effect on proliferation, motility, and migration}

In this study, we showed that a GFAP $\delta$-induced collapse of the IF network results in a reorganization of the whole IF network. This is in contrast with a knockout or knockdown of GFAP, which does not severely affect vimentin or nestin localization [40]. GFAP, as well as other IFs, has been linked to changes in proliferation and astrocyte motility, but it has to be noted that the studies on the role of GFAP in cell proliferation are inconclusive. A GFAP knockdown has been shown to lead to an increase in proliferation in some studies [4, 60], but not in others [61]. On the other hand, astrocyte cultures of transgenic mice overexpressing human GFAP $\alpha$ showed a decrease in proliferation [62]. Since GFAP $\delta$ is expressed in cycling cells in the human brain $[8,12,14]$, we expected an effect of GFAP $\delta$ on cell proliferation. Unexpectedly, we observed that not the expression of GFAP $\delta$, but an enhanced expression of GFAP $\alpha$ resulted in a significant increase in proliferation of primary astrocytes. We detected a similar trend in the U251 astrocytoma cells. Our data show that the increase in proliferation is caused by the mere increase in GFAP $\alpha$ and that there is no direct role of GFAP $\delta$ in cell proliferation in cells with a collapsed IF network. Lowering the ratio of GFA$\mathrm{P} \alpha$ :GFAP $\delta$ making sure that there is still an intact network also did not change cell proliferation in vitro [40].

Several studies have found that a knockdown or knockout of GFAP increases cell motility [4, 43, 63]. In addition, we recently showed that a specific knockdown of GFAP $\alpha$ leads to a reduced motility in astrocytoma cells [40].Here, we show that an overexpression of GFAP $\alpha$ or GFAP $\delta$ has no effect on cell motility, even if the IF network is collapsed by high GFAP $\delta$ levels. Regulation of motility by GFAP is rather complex. Mutations in the rod domain of GFAP that causes collapses of the network, and thus mimics our GFAP $\delta$ condition, have been shown to increase cell motility. In contrast, mutations in the tail domain of GFAP had no effect on motility [64, 65]. GFAP $\alpha$ and GFAP $\delta$ only differ in the C-terminal tail, thus this might explain why we do not see differences in cell motility.

\section{Effect on ECM interaction}

GFAP has been linked to cell morphological changes in astrocytes in vitro, where a correlation was observed between the level of GFAP expression and the number of cell protrusions $[4,41-43,61]$. In reactive gliosis, the production of GFAP as well as other IF proteins is upregulated. This results in a more pronounced, GFAPpositive, IF network [66-68]. Here, we show that the collapse of the IF network due to GFAP $\delta$ expression resulted in more round cells with longer focal adhesions in vitro. This change resembles the morphological change in astrocytes devoid of IFs in vitro [4, 41, 43, 61]. Thus, an intact IF network is important for the formation or stabilization of processes of cells. In our earlier study, we showed, however, that a pan-GFAP knockdown in U373 cells did not result in a rounder morphology [40]. This is probably due to the presence of an intact vimentin and nestin IF network, which is lacking in the cells with a GFAP $\delta$-induced collapse.

The change we observed in cell morphology in cells with a GFAP $\delta$-induced collapsed IF network shows that the IF network distribution per se can affect the shape of the cell. The way GFAP $\delta$ alters shape is likely to occur through integrins. Integrins are the main linkers between the extracellular matrix and the cytoskeleton in vivo and, together with other proteins, they form the focal adhesions. Focal adhesions can be present in different sizes and maturation states, ranging from small structures, of less than $1 \mu \mathrm{m}$, to larger focal adhesions. Focal adhesion size is dependent on actomyosin generated tension [69, 70]. Indeed, interactions between the IF protein vimentin and mature focal adhesions have been shown to be essential for proper cell spreading [71]. Vimentin can regulate adhesion and focal contact size under shear stress [72] and controls cell adhesion strength through plectin and $\beta 3$ integrins [73]. Thus, GFAP could have a similar function in adhesion of astrocytes to the ECM and in this way alter cell shape. Our data confirm a direct effect of the IF constellation on focal adhesions and cell-matrix interactions, as both GFAP isoforms increase focal adhesion size. Since only GFAP $\delta$ expressing cells showed altered morphology, this implies a difference in the effect GFAP $\alpha$ and GFAP $\delta$ has on the functionality of focal adhesions. This might partly be due to differences in production of ECM molecules, such as laminin, as we have shown before [40]. Although the exact interaction of GFAP with focal adhesions is still elusive, interactions between other IFs and 

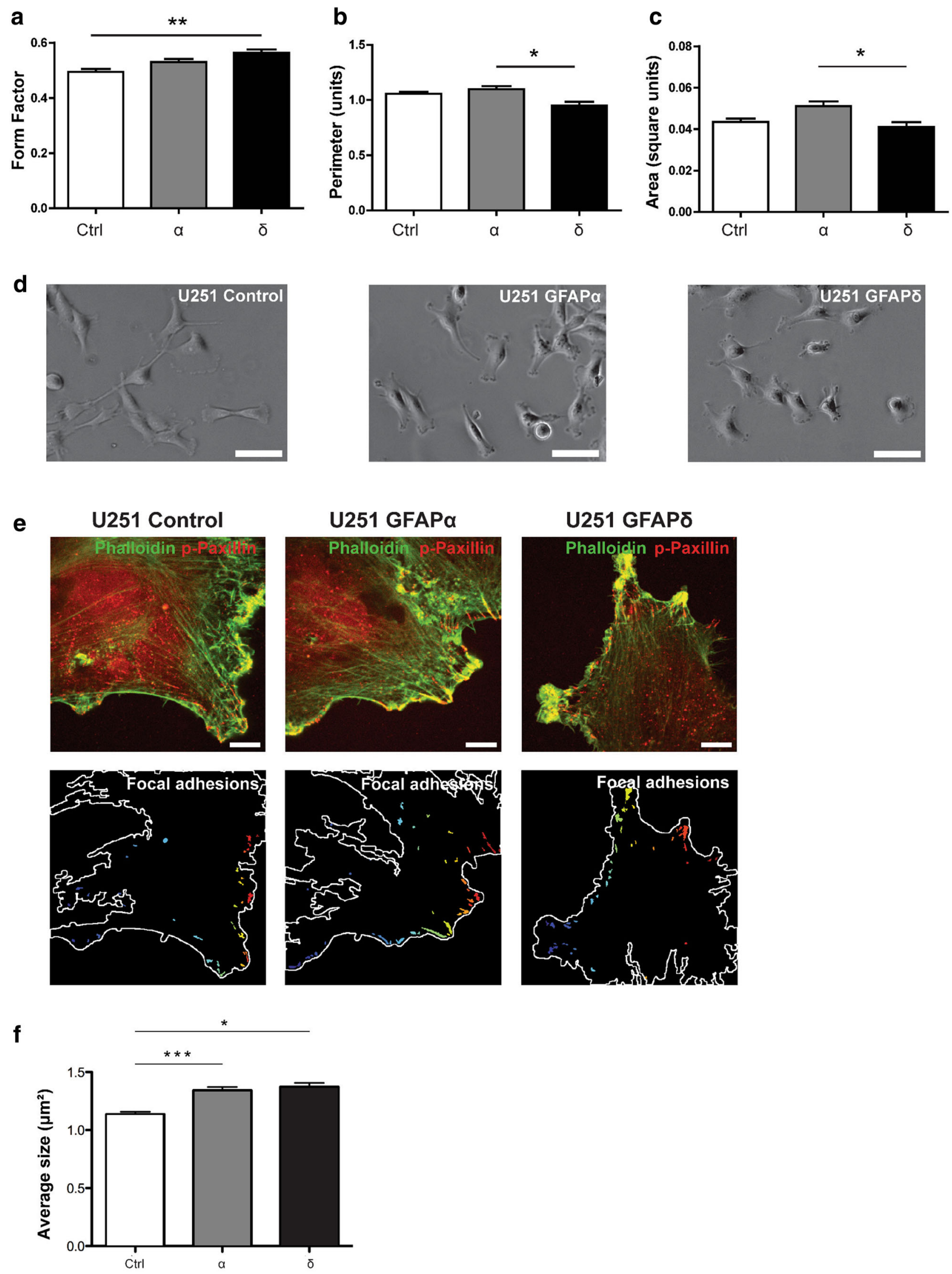
Fig. 6 Morphology of U251 cells with different IF networks. a GFAP $\delta$ expressing cells showed a more round morphology in comparison to the control $(p=0.009)$ as is measured by the form factor of these cells. Significant differences between GFAP $\alpha$ and GFAP $\delta$ were found in $\mathbf{b}$ perimeter $(p=0.02)$ and $\mathbf{c}$ area $(p=0.03)$. Bars show mean and SEM $(n=5)$. d Phase contrast pictures showing the more round morphology of the GFAP $\delta$ expressing cells in comparison with the control vector and GFAP $\alpha$. Scale bars represent $100 \mu \mathrm{m}$. e U251 cells expressing different GFAP isoforms are stained for actin with phalloidin (green) and phosphorylated paxillin (red). Scale bars represent $10 \mu \mathrm{m}$. The lower panel shows focal adhesions (overlap of phalloidin and phosphorylated paxillin). $\mathbf{f}$ Quantification of focal adhesion shows larger focal adhesion size in GFAP $\alpha$ ( $p=0.0001)$ and GFAP $\delta(p=0.001)$ expressing cells compared with the control mCherry (mCherry: $1.13 \mu \mathrm{m}^{2} \pm 0.02 n=735$; GFAP $\alpha$ : $1.34 \mu \mathrm{m}^{2} \pm 0.03 n=994$; GFAP $8: 1.37 \mu \mathrm{m}^{2} \pm 0.03 n=828$
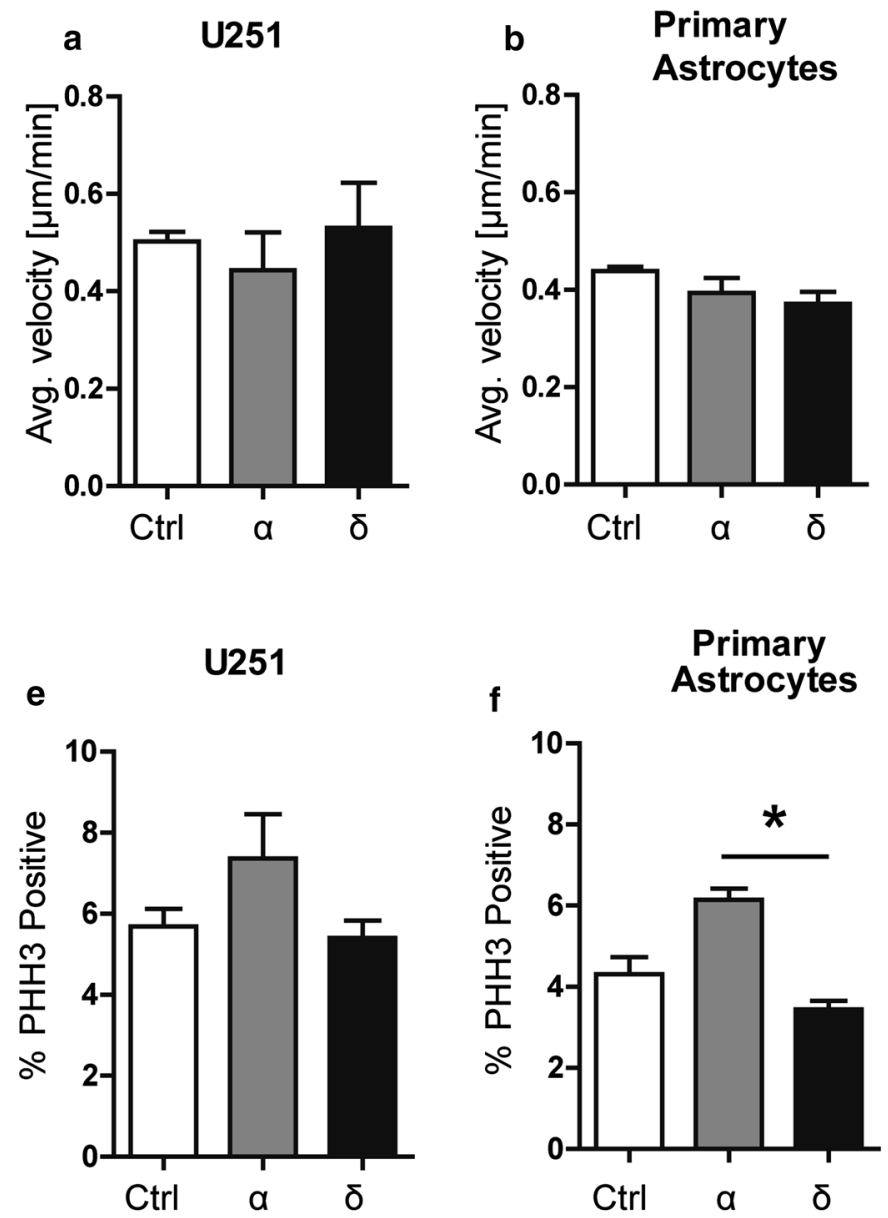

Fig. 7 Migration and proliferation is not affected by GFAP $\delta$. a Single cell motility was measured as the average velocity in $\mu \mathrm{m} / \mathrm{min}$ of a single cell, in a sequence of images, which were taken overnight. Average velocity did not differ significantly between GFAP $\alpha$, GFAP $\delta$, and control cells $(p=0.9)(n=3)$ in U251 cells or in b primary astrocytes $(p=0.15) \quad(n=3)$. c Proliferation was measured by metabolic conversion of MTT, which was measured by absorbance of light. The absorbance at $t=24 \mathrm{~h}$ was put at $100 \%$. There was no significant difference between GFAP $\delta$, GFAP $\alpha$, and control $(p=0.56)(n=3)$ at $48 \mathrm{~h}$ in $\mathrm{U} 251$ cells or d primary astrocytes $(p=0.56)(n=3)$. e Cells were stained for PHH3, focal adhesions have been described, as is nicely reviewed by Leube et al. [74].

\section{Conclusion}

To summarize, we have shown that a GFAP $\delta$-induced collapse of the IF network has a profound effect on IF network morphology, increases focal adhesion size, and changes the IF network dynamics, without altering astrocyte motility or proliferation. Although GFAP $\delta$ is expressed in more proliferative cell types with a higher migration potential, GFAP $\delta$ itself does not directly
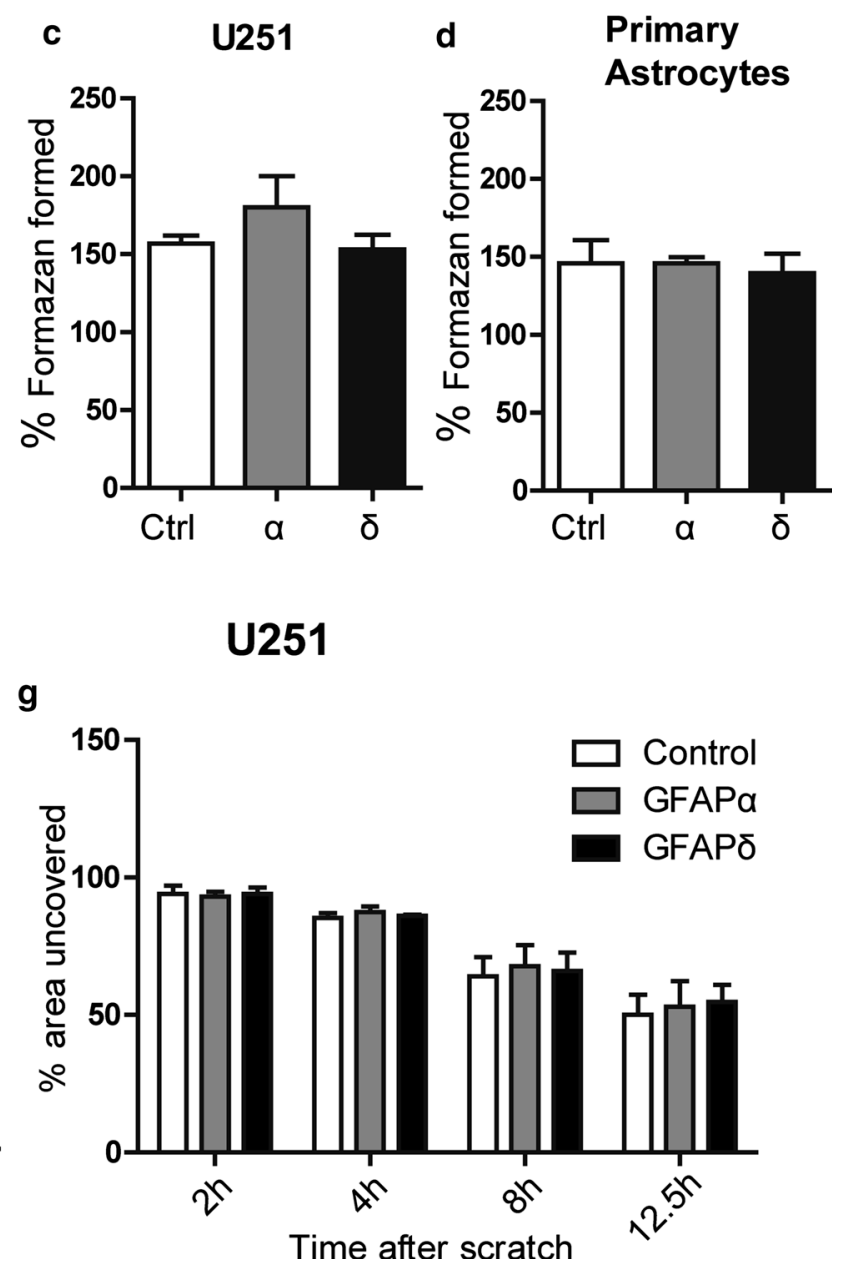

indicating dividing cells. The average percentage of dividing cells per condition at one time point is not significantly different in cells with GFAP $\alpha, \operatorname{GFAP} \delta$, and control in U251 cells $(p=0.21)(n=4)(\mathbf{f})$. In primary astrocytes, there was a significant difference in proliferation between GFAP $\alpha$ and GFAP $\delta(p=0.04)(n=3)$. g Scratch assays were done by scratching a monolayer of cells and measuring the area uncovered by cells, over time. The area of the scratch at $t=0$ was put at $100 \%$. The bars represent the area where there are no cells at different time points. There was no significant difference $(p=0.7)$ $(n=3)$ between GFAP $\alpha$, GFAP $\delta$, and the control after $12.5 \mathrm{~h}$. All graphs show mean with SEM 
influence proliferation or migration when there is a collapse of the IF network. The changes in IF network dynamics could hold clues to GFAP isoform specific functions.

Acknowledgments The authors would like to thank Jan Stap of the Cellular Imaging facility of the AMC in Amsterdam for important technical assistance and scientific discussions. We are grateful to Linda Hoogland for indispensible optimization of experiments. The authors would also like to thank R. Toonen (VU University, Amsterdam, The Netherlands) for the IRES2 constructs. Human postmortem brain material was obtained from the Netherlands Brain Bank (NBB). We also like to thank B. Hooibrink of the Cellular Imaging facility of the AMC for the cell sorting, J. Ruijter for statistical advice and W. Kamphuis for critically reading the manuscript and discussions.

This work was supported by FOM Grant 09MMC06, NANONET COST [BM1002] and the Netherlands Organization for Scientific Research [NWO; VICI Grant 865.09.003].

Open Access This article is distributed under the terms of the Creative Commons Attribution 4.0 International License (http:// creativecommons.org/licenses/by/4.0/), which permits unrestricted use, distribution, and reproduction in any medium, provided you give appropriate credit to the original author(s) and the source, provide a link to the Creative Commons license, and indicate if changes were made.

\section{References}

1. Goldman RD, Grin B, Mendez MG, Kuczmarski ER (2008) Intermediate filaments: versatile building blocks of cell structure. Curr Opin Cell Biol 20:28-34. doi:10.1016/j.ceb.2007.11.003

2. Ivaska J, Pallari H-M, Nevo J, Eriksson JE (2007) Novel functions of vimentin in cell adhesion, migration, and signaling. Exp Cell Res 313:2050-2062. doi:10.1016/j.yexcr.2007.03.040

3. Pekny M (2001) Astrocytic intermediate filaments: lessons from GFAP and vimentin knock-out mice. Prog Brain Res 132:23-30. doi:10.1016/S0079-6123(01)32062-9

4. Rutka JT, Hubbard SL, Fukuyama K et al (1994) Effects of antisense glial fibrillary acidic protein complementary DNA on the growth, invasion, and adhesion of human astrocytoma cells. Cancer Res 54:3267-3272

5. Kamphuis W, Mamber C, Moeton M et al (2012) GFAP isoforms in adult mouse brain with a focus on neurogenic astrocytes and reactive astrogliosis in mouse models of Alzheimer disease. PLoSOne 7:e42823. doi:10.1371/journal.pone.0042823

6. Middeldorp J, Hol EM (2011) GFAP in health and disease. Prog Neurobiol 93:421-443. doi:10.1016/j.pneurobio.2011.01.005

7. Roelofs RF, Fischer DF, Houtman SH et al (2005) Adult human subventricular, subgranular, and subpial zones contain astrocytes with a specialized intermediate filament cytoskeleton. Glia 52:289-300. doi:10.1002/glia.20243

8. Van den Berge SA, Middeldorp J, Zhang CE et al (2010) Longterm quiescent cells in the aged human subventricular neurogenic system specifically express GFAP-delta. Aging Cell 9:313-326. doi:10.1111/j.1474-9726.2010.00556.x

9. Van Strien ME, Sluijs JA, Reynolds BA et al (2014) Isolation of neural progenitor cells from the human adult subventricular zone based on expression of the cell surface marker CD271. Stem Cells Transl Med 3:470-480. doi:10.5966/sctm.2013-0038
10. Hol EM, Pekny M (2015) Glial fibrillary acidic protein (GFAP) and the astrocyte intermediate filament system in diseases of the central nervous system. Curr Opin Cell Biol 32:121-130. doi:10. 1016/j.ceb.2015.02.004

11. Andreiuolo F, Junier MP, Hol EM et al (2009) GFAPdelta immunostaining improves visualization of normal and pathologic astrocytic heterogeneity. Neuropathology 29:31-39. doi:10.1111/ j.1440-1789.2008.00936.x

12. Choi KC, Kwak SE, Kim JE et al (2009) Enhanced glial fibrillary acidic protein-delta expression in human astrocytic tumor. Neurosci Lett 463:182-187. doi:10.1016/j.neulet.2009.07.076

13. Martinian L, Boer K, Middeldorp J et al (2009) Expression patterns of glial fibrillary acidic protein (GFAP)-delta in epilepsyassociated lesional pathologies. Neuropathol Appl Neurobiol 35:394-405. doi:10.1111/j.1365-2990.2009.00996.x

14. Heo DH, Kim SH, Yang KM et al (2012) A histopathological diagnostic marker for human spinal astrocytoma: expression of glial fibrillary acidic protein-delta. J Neurooncol 108:45-52. doi:10.1007/s11060-012-0801-z

15. Kamphuis W, Middeldorp J, Kooijman L et al (2014) Glial fibrillary acidic protein isoform expression in plaque related astrogliosis in Alzheimer's disease. Neurobiol Aging 35:492-510. doi:10.1016/j.neurobiolaging.2013.09.035

16. Nielsen AL, Jorgensen AL (2004) Self-assembly of the cytoskeletal glial fibrillary acidic protein is inhibited by an isoform-specific C terminus. J Biol Chem 279:41537-41545. doi:10. 1074/jbc.M406601200

17. Perng MD, Wen SF, Gibbon T et al (2008) Glial fibrillary acidic protein filaments can tolerate the incorporation of assemblycompromised GFAP-delta, but with consequences for filament organization and alphaB-crystallin association. Mol Biol Cell 19:4521-4533. doi:10.1091/mbc.E08-03-0284

18. Kreplak L, Fudge D (2007) Biomechanical properties of intermediate filaments: from tissues to single filaments and back. BioEssays 29:26-35. doi:10.1002/bies.20514

19. Herrmann H, Strelkov SV, Burkhard P, Aebi U (2009) Intermediate filaments: primary determinants of cell architecture and plasticity. J Clin Invest 119:1772-1783. doi:10.1172/JCI38214

20. Blikstad I, Lazarides E (1983) Vimentin filaments are assembled from a soluble precursor in avian erythroid cells. J Cell Biol 96:1803-1808. doi:10.1083/jcb.96.6.1803

21. Soellner P, Quinlan RA, Franke WW (1985) Identification of a distinct soluble subunit of an intermediate filament protein: tetrameric vimentin from living cells. Proc Natl Acad Sci 82:7929-7933

22. Lu X (1993) Network incorporation of intermediate filament molecules differs between preexisting and newly assembling filaments. Exp Cell Res 208:218-225. doi:10.1006/excr.1993. 1240

23. Colakoglu G, Brown A (2009) Intermediate filaments exchange subunits along their length and elongate by end-to-end annealing. J Cell Biol 185:769-777

24. Chou YH, Rosevear E, Goldman RD (1989) Phosphorylation and disassembly of intermediate filaments in mitotic cells. Proc Natl Acad Sci 86:1885-1889

25. Ku N-O, Liao J, Chou C-F, Omary MB (1996) Implications of intermediate filament protein phosphorylation. Cancer Metastasis Rev 15:429-444. doi:10.1007/BF00054011

26. Goto H, Kosako H, Inagaki M (2000) Regulation of intermediate filament organization during cytokinesis: possible roles of Rhoassociated kinase. MicroscResTech 49:173-182. doi:10.1002/ (SICI)1097-0029(20000415)49:2<173:AID-JEMT10>3.0.CO;2A

27. Izawa I, Inagaki M (2006) Regulatory mechanisms and functions of intermediate filaments: a study using site- and phosphorylation 
state-specific antibodies. Cancer Sci 97:167-174. doi:10.1111/j. 1349-7006.2006.00161.x

28. Omary MB, Ku NO, Tao GZ et al (2006) "Heads and tails" of intermediate filament phosphorylation: multiple sites and functional insights. Trends Biochem 31:383-394. doi:10.1016/j.tibs. 2006.05.008

29. Perng MD, Su M, Wen SF et al (2006) The Alexander diseasecausing glial fibrillary acidic protein mutant, R416W, accumulates into Rosenthal fibers by a pathway that involves filament aggregation and the association of alpha B-crystallin and HSP27. Am J Hum Genet 79:197-213. doi:10.1086/504411

30. Brenner M, Johnson AB, Boespflug-Tanguy O et al (2001) Mutations in GFAP, encoding glial fibrillary acidic protein, are associated with Alexander disease. Nat Genet 27:117-120. doi: $10.1038 / 83679$

31. Goldman JE, Corbin E (1988) Isolation of a major protein component of Rosenthal fibers. Am J Pathol 130:569-578

32. Iwaki T, Kume-Iwaki A, Liem RKH, Goldman JE (1989) $\alpha \mathrm{B}-$ crystallin is expressed in non-lenticular tissues and accumulates in Alexander's disease brain. Cell 57:71-78. doi:10.1016/00928674(89)90173-6

33. Tomokane N, Iwaki T, Tateishi J et al (1991) Rosenthal fibers share epitopes with alpha B-crystallin, glial fibrillary acidic protein, and ubiquitin, but not with vimentin. Immunoelectron microscopy with colloidal gold. Am J Pathol 138:875-885

34. Tang G, Xu Z, Goldman JE (2006) Synergistic effects of the SAPK/JNK and the proteasome pathway on glial fibrillary acidic protein (GFAP) accumulation in Alexander disease. J Biol Chem 281:38634-38643. doi:10.1074/jbc.M604942200

35. Tian R, Gregor M, Wiche G, Goldman JE (2006) Plectin regulates the organization of glial fibrillary acidic protein in Alexander disease. Am J Pathol 168:888-897. doi:10.2353/ ajpath.2006.051028

36. Hagemann TL, Boelens WC, Wawrousek EF, Messing A (2009) Suppression of GFAP toxicity by B-crystallin in mouse models of Alexander disease. Hum Mol Genet 18:1190-1199. doi:10.1093/ hmg/ddp013

37. Tian R, Wu X, Hagemann TL et al (2010) Alexander disease mutant glial fibrillary acidic protein compromises glutamate transport in astrocytes. J Neuropathol Exp Neurol 69:335-345. doi:10.1097/NEN.0b013e3181d3cb52

38. Chen Y-S, Lim S-C, Chen M-H et al (2011) Alexander disease causing mutations in the C-terminal domain of GFAP are deleterious both to assembly and network formation with the potential to both activate caspase 3 and decrease cell viability. Exp Cell Res 317:2252-2266. doi:10.1016/j.yexcr.2011.06.017

39. Sosunov AA, Guilfoyle E, Wu X et al (2013) Phenotypic conversions of "Protoplasmic" to "Reactive" astrocytes in Alexander disease. J Neurosci 33:7439-7450. doi:10.1523/ JNEUROSCI.4506-12.2013

40. Moeton M, Kanski R, Stassen OMJA et al (2014) Silencing GFAP isoforms in astrocytoma cells disturbs laminin-dependent motility and cell adhesion. FASEB J Off Publ Fed Am Soc Exp Biol 28:2942-2954. doi:10.1096/fj.13-245837

41. Rutka JT, Smith SL (1993) Transfection of human astrocytoma cells with glial fibrillary acidic protein complementary DNA: analysis of expression, proliferation, and tumorigenicity. Cancer Res 53:3624-3631

42. Elobeid A, Bongcam-Rudloff E, Westermark B, Nister M (2000) Effects of inducible glial fibrillary acidic protein on glioma cell motility and proliferation. J Neurosci Res 60:245-256. doi:10. 1002/(SICI)1097-4547(20000415)60:2<245:AID-JNR14>3.0. $\mathrm{CO} ; 2-1$

43. Lepekhin EA, Eliasson C, Berthold $\mathrm{CH}$ et al (2001) Intermediate filaments regulate astrocyte motility. J Neurochem 79:617-625
44. Klioueva NM, Rademaker MC, Dexter DT et al (2015) BrainNet Europe's code of conduct for brain banking. J Neural Transm. doi:10.1007/s00702-014-1353-5

45. Naldini L, Blomer U, Gallay P et al (1996) In vivo gene delivery and stable transduction of nondividing cells by a lentiviral vector. Science 272:263-267

46. Naldini L, Blomer U, Gage FH et al (1996) Efficient transfer, integration, and sustained long-term expression of the transgene in adult rat brains injected with a lentiviral vector. Proc Natl Acad Sci USA 93:11382-11388

47. Mosmann T (1983) Rapid colorimetric assay for cellular growth and survival: application to proliferation and cytotoxicity assays. J Immunol Methods 65:55-63

48. Thurston G, Jaggi B, Palcic B (1988) Measurement of cell motility and morphology with an automated microscope system. Cytometry 9:411-417. doi:10.1002/cyto.990090502

49. Ruijter JM, Thygesen HH, Schoneveld OJ et al (2006) Factor correction as a tool to eliminate between-session variation in replicate experiments: application to molecular biology and retrovirology. Retrovirology 3:2. doi:10.1186/1742-4690-3-2

50. Yoon M, Moir RD, Prahlad V, Goldman RD (1998) Motile properties of vimentin intermediate filament networks in living cells. J Cell Biol 143:147-157

51. Yoon KH, Yoon M, Moir RD et al (2001) Insights into the dynamic properties of keratin intermediate filaments in living epithelial cells. J Cell Biol 153:503-516. doi:10.1083/jcb.153.3.503

52. Li H, Guo Y, Teng J et al (2006) 14-3-3 $\gamma$ affects dynamics and integrity of glial filaments by binding to phosphorylated GFAP. J Cell Sci 119:4452-4461. doi:10.1242/jcs.03219

53. Gilchrist S, Gilbert N, Perry P et al (2004) Altered protein dynamics of disease-associated lamin A mutants. BMC Cell Biol 5:46. doi:10.1186/1471-2121-5-46

54. Moir RD, Yoon M, Khuon S, Goldman RD (2000) Nuclear lamins A and B1: different pathways of assembly during nuclear envelope formation in living cells. J Cell Biol 151:1155-1168

55. Kreplak L, Aebi U, Herrmann H (2004) Molecular mechanisms underlying the assembly of intermediate filaments. Exp Cell Res 301:77-83. doi:10.1016/j.yexcr.2004.08.021

56. Nakamura Y, Takeda M, Aimoto S et al (1992) Assembly regulatory domain of glial fibrillary acidic protein. A single phosphorylation diminishes its assembly-accelerating property. J Biol Chem 267:23269-23274

57. Skalli O, Chou Y-H, Goldman RD (1992) Intermediate filaments: not so tough after all. Trends Cell Biol 2:308-312. doi:10.1016/ 0962-8924(92)90121-3

58. Chen WJ, Liem RK (1994) The endless story of the glial fibrillary acidic protein. J Cell Sci 107:2299-2311

59. Chou YH, Opal P, Quinlan RA, Goldman RD (1996) The relative roles of specific $\mathrm{N}$ - and $\mathrm{C}$-terminal phosphorylation sites in the disassembly of intermediate filament in mitotic BHK-21 cells. J Cell Sci 109:817-826

60. Ding M, Eliasson C, Betsholtz C et al (1998) Altered taurine release following hypotonic stress in astrocytes from mice deficient for GFAP and vimentin. Brain Res Mol Brain Res 62:77-81

61. Weinstein DE, Shelanski ML, Liem RK (1991) Suppression by antisense mRNA demonstrates a requirement for the glial fibrillary acidic protein in the formation of stable astrocytic processes in response to neurons. J Cell Biol 112:1205-1213

62. Cho W, Messing A (2009) Properties of astrocytes cultured from GFAP over-expressing and GFAP mutant mice. Exp Cell Res 315:1260-1272. doi:10.1016/j.yexcr.2008.12.012

63. Rutka JT, Ackerley C, Hubbard SL et al (1998) Characterization of glial filament-cytoskeletal interactions in human astrocytomas: an immuno-ultrastructural analysis. Eur J Cell Biol 76:279-287. doi:10.1016/S0171-9335(98)80006-X 
64. Yoshida T, Tomozawa Y, Arisato T et al (2007) The functional alteration of mutant GFAP depends on the location of the domain: morphological and functional studies using astrocytomaderived cells. J Hum Genet 52:362-369. doi:10.1007/s10038007-0124-7

65. Yoshida T, Sasayama H, Nakagawa M (2009) The process of inducing GFAP aggregates in astrocytoma-derived cells is different between R239C and R416W mutant GFAP. A time-lapse recording study. Neurosci Lett 458:11-14. doi:10.1016/j.neulet. 2009.04.032

66. Wilhelmsson U, Bushong EA, Price DL et al (2006) Redefining the concept of reactive astrocytes as cells that remain within their unique domains upon reaction to injury. Proc Natl Acad Sci USA 103:17513-17518. doi:10.1073/pnas.0602841103

67. Sofroniew MV (2009) Molecular dissection of reactive astrogliosis and glial scar formation. Trends Neurosci 32:638-647. doi:10.1016/j.tins.2009.08.002

68. Buffo A, Rolando C, Ceruti S (2010) Astrocytes in the damaged brain: molecular and cellular insights into their reactive response and healing potential. Biochem Pharmacol 79:77-89. doi:10. 1016/j.bcp.2009.09.014
69. Bershadsky AD, Balaban NQ, Geiger B (2003) Adhesion-dependent cell mechanosensitivity. Annu Rev Cell Dev Biol 19:677-695. doi:10.1146/annurev.cellbio.19.111301.153011

70. Wolfenson H, Bershadsky A, Henis YI, Geiger B (2011) Actomyosin-generated tension controls the molecular kinetics of focal adhesions. J Cell Sci 124:1425-1432. doi:10.1242/jcs.077388

71. Lynch CD, Lazar AM, Iskratsch T et al (2012) Endoplasmic spreading requires coalescence of vimentin intermediate filaments at force-bearing adhesions. Mol Biol Cell 24:21-30. doi:10.1091/mbc.E12-05-0377

72. Tsuruta D, Jones JCR (2003) The vimentin cytoskeleton regulates focal contact size and adhesion of endothelial cells subjected to shear stress. J Cell Sci 116:4977-4984. doi:10.1242/jcs.00823

73. Bhattacharya R, Gonzalez AM, DeBiase PJ et al (2009) Recruitment of vimentin to the cell surface by 3 integrin and plectin mediates adhesion strength. J Cell Sci 122:1390-1400. doi: $10.1242 /$ jcs. 043042

74. Leube RE, Moch M, Windoffer R (2015) Intermediate filaments and the regulation of focal adhesion. Curr Opin Cell Biol 32:13-20. doi:10.1016/j.ceb.2014.09.011 